\title{
Enhanced fibrillin-2 expression is a general feature of wound healing and sclerosis: potential alteration of cell attachment and storage of TGF- $\beta$
}

\author{
Jürgen Brinckmann ${ }^{1,2}$, Nico Hunzelmann ${ }^{3}$, Birgit Kahle ${ }^{1}$, Jürgen Rohwedel ${ }^{2}$, Jan Kramer ${ }^{2,4}$, Mark A Gibson ${ }^{5}$, \\ Dirk Hubmacher ${ }^{6}$ and Dieter P Reinhardt ${ }^{6}$
}

\begin{abstract}
Wound healing and sclerosis are characterized by an increase of extracellular matrix proteins, which are characteristically expressed in the embryo-fetal period. We analyzed the expression of fibrillin-2, which is typically found in embryonic tissues, but only scarcely in adult skin. In wound healing and sclerotic skin diseases such as lipodermatosclerosis and scleroderma, a marked increase of fibrillin-2 expression was found by immunohistology. Double labelling of fibrillin-2 and tenascin- $\mathrm{C}$, which is also expressed in wound healing and sclerosis, showed co-localization of both proteins. Solid-phase and slot blot-overlay assays showed a dose-dependent binding of the recombinant N-terminal half of fibrillin-2 (rFBN2-N) to tenascin-C. Real-time PCR showed an increase of the fibrillin-2 gene expression in cell culture triggered by typical mediators for fibroblast activation such as serum, IL-4, and TGF- $\beta$. By contrast, prolonged hypoxia is not associated with changes in fibrillin-2 expression. Tenascin- $\mathrm{C}$ is an anti-adhesive substrate for fibroblasts, whereas fibrillin-2 stimulates cell attachment. Attachment assays using mixed substrates showed decreased cell attachment when tenascin- $\mathrm{C}$ and $\mathrm{rFBN2}-\mathrm{N}$ were coated together, compared with the attachment to rFBN2-N alone. Fibrillins are involved in storage and activation of TGF- $\beta$. Immunohistology with an antibody against the latency-associated peptide (LAP (TGF- $\beta 1$ )) showed a marked increase of inactive LAP-bound TGF- $\beta 1$ in wound healing and sclerotic skin whereas normal skin showed only a weak expression. Double immunofluorescence confirmed a partial colocalization of both proteins. In conclusion, we show that a stimulation of the fibrillin-2 expression is a characteristic feature of fibroblasts present in wound healing and sclerosis, which may be involved in the alteration of cell attachment and storage of inactive TGF- $\beta$ in the matrix.
\end{abstract}

Laboratory Investigation (2010) 90, 739-752; doi:10.1038/labinvest.2010.49; published online 1 March 2010

KEYWORDS: fibrillin; sclerosis; wound healing

Fibrillins constitute a family of extracellular glycoproteins comprising fibrillin-1,2 and 3. All fibrillins are characterized by a modular domain organization with a homology of $61-69 \%$ on the amino acid level. The most frequent domains are calcium-binding epidermal growth factor-like domains (cbEGF) and transforming growth factor- $\beta$ (TGF- $\beta$ ) binding protein domains (TB). Fibrillins are central constituents of $10-12 \mathrm{~nm}$ in diameter microfibrils found in most tissues and are thought to provide a scaffold for the deposition of tropoelastin, the precursor of mature cross-linked elastin. Furthermore, fibrillins are involved in the storage and regu- lation of growth factors such as TGF- $\beta$ s and BMPs. ${ }^{1-3}$ All fibrillins contain a cell attachment arginine-glycine-aspartate (RGD) site in the fourth TB domain. Both, fibrillin-2 and fibrillin-3 contain one additional RGD site either in the third TB domain (fibrillin-2) or in the eighteenth calcium-binding epidermal growth factor-like domain (fibrillin-3). For fibrillin-1 and -2 , RGD-mediated cell binding has been established. ${ }^{4-6}$ In addition, cell adhesion to the $\mathrm{N}$ terminus of fibrillin- 1 is mediated by the heparin/heparan sulphate-binding site. ${ }^{7,8}$

Mutations in the fibrillin-1 gene give rise to Marfan syndrome and other heritable connective tissue disorder

\footnotetext{
${ }^{1}$ Department of Dermatology, University of Lübeck, Lübeck, Germany; ${ }^{2}$ Department of Virology and Cell Biology, University of Lübeck, Lübeck, Germany; ${ }^{3}$ Department of Dermatology, University of Cologne, Cologne, Germany; ${ }^{4}$ Medical Clinic I, University of Lübeck, Lübeck, Germany; ${ }^{5}$ Discipline of Pathology, School of Medical Sciences, University of Adelaide, Australia and ${ }^{6}$ Department of Anatomy and Cell Biology and Faculty of Dentistry, McGill University, Montreal, Canada

Correspondence: Dr J Brinckmann, MD, Department of Dermatology, Department of Virology and Cell Biology, University of Lübeck, Ratzeburger Allee 160, D-23538 Lübeck, Germany.

E-mail: brinckmann@molbio.uni-luebeck.de

Received 9 March 2009; revised 20 January 2010; accepted 20 January 2010
} 
generally characterized by cardiovascular, ocular, and skeletal symptoms. Congenital contractural arachnodactyly or BealsHecht syndrome is caused by mutations in the fibrillin-2 gene. Currently, it is not established whether deficiencies of fibrillin-3 also result in a human genetic disorder. ${ }^{9}$ Fibrillins are expressed in a distinct temporal and tissue-specific expression pattern during mammalian development. ${ }^{1}$ Fibrillin-1 is expressed in most connective tissues both in the embryo-fetal period and throughout postnatal life. The expression pattern of fibrillin-2 is largely restricted to developing fetal tissues. However, during the embryo-fetal period fibrillin-1 and fibrillin-2 are often co-expressed in many tissues such as skin, lung, heart, aorta, central nervous system anlage, but are differently expressed in other tissues such as kidney, liver, rib anlagen, and elastic cartilage. ${ }^{10}$ Similarly, fibrillin-3 is expressed mostly in fetal tissues but its physiological function is currently unknown. ${ }^{11}$

The well orchestrated process of wound healing leading to a scar and the often recalcitrant process of fibrosis are characterized by increased production of extracellular matrix proteins, which are normally expressed during the embryo-fetal period. Fetal skin for example, is characterized by a higher collagen III/I ratio compared with adult skin, a pattern that was also documented for wound healing and sclerotic skin diseases, especially in the initial inflammatory stage. ${ }^{12-14}$ Furthermore, collagen cross-links in healing skin wounds and in sclerotic skin of hypertrophic scars, lipodermatosclerosis (LDS) and scleroderma are characterized by a shift from lysine-aldehyde derived cross-links primarily observed in adult skin to hydroxylysine-aldehyde derived cross-links characteristic for fetal skin. ${ }^{15-17}$ Also, for several non-collagenous matrix proteins an increase of embryo-fetal proteins was reported in wound healing and sclerosis: The splice variant EDA of fibronectin, a $440 \mathrm{kDa}$ adhesive matrix glycoprotein characterized by an additional type III repeat between repeats 11 and 12 , is expressed in the developing embryo, but is barely detectable in adult skin. EDA was also found in wound healing and sclerosis and together with TGF- $\beta$ is thought to be important for the generation of myofibroblasts. ${ }^{18,19}$ Similarly, tenascin-C, a large hexameric $(\sim 1800 \mathrm{kDa})$ extracellular glycoprotein, is expressed at high levels during embryonic development and fibroproliferative processes such as wound healing and sclerosis. ${ }^{20}$ Tenascin-C binds to fibronectin, acts as an anti-adhesive protein for cells and appears to be involved in the generation of myofibroblasts in wound healing. ${ }^{21}$

In this paper we have analyzed the expression of fibrillin-2 in wound healing and sclerotic skin diseases. We provide evidence by immunohistology that fibrillin-2 is expressed in LDS, scleroderma and wound healing. It shows a co-localization with tenascin- $\mathrm{C}$ and the interaction of both proteins alters cell adhesiveness. Furthermore, the increased expression of fibrillin-2 is accompanied by higher expression levels of latent TGF- $\beta$ complex.

\section{MATERIALS AND METHODS}

\section{Tissue Samples}

Skin biopsies were obtained from patients with lipodermatosclerosis, scleroderma, and melanoma re-excision scars free of melanoma (scar age about 14 days) (for each $n=5$ ). Normal skin was obtained from patients undergoing plastic surgery $(n=5)$. The procedure was approved by the local ethics committee, and informed consent was obtained from the tissue donors. Specimens underwent routine paraffin processing after formalin fixation.

\section{Immunohistology}

The monoclonal antibody against tenascin-C (clone DB7, Biomol, Germany) and the polyclonal antibody against LAP (TGF- $\beta 1$ ) raised in goat (AF-246-NA, R\&D systems, USA) were obtained from commercial sources. The polyclonal rabbit antiserum against the recombinant C-terminal fragments of human fibrillin-1 and fibrillin-2 have been described and characterized previously. ${ }^{22,23}$ Alkaline phosphatase anti-alkaline phosphatase (APAAP)-neufuchsin staining of paraffin sections was performed as follows. For fibrillin staining, sections were pre-treated with $100 \mu \mathrm{g} / \mathrm{ml}$ protease from Streptomyces griseus (P6911, Sigma, USA) in $50 \mathrm{mM}$ Tris, $150 \mathrm{mM} \mathrm{NaCl}, \mathrm{pH} 7.4$ (TBS) for $15 \mathrm{~min}$ at $37^{\circ} \mathrm{C}$, and $0.5 \mathrm{mg} / \mathrm{ml}$ pancreatic elastase (E6883, Sigma) in TBS for $45 \mathrm{~min}$ at $20^{\circ} \mathrm{C}$. For tenascin-C staining, only a digestion step with the S. griseus protease was performed. Non-specific binding sites were blocked with $10 \%(\mathrm{v} / \mathrm{v})$ fetal calf serum. Skin sections were incubated with primary antibodies for $1 \mathrm{~h}$ (anti-fibrillin-1 and anti-fibrillin-2 1:1000, anti-tenascin-C 1:200, diluted in TBS). Mouse anti-rabbit antibody (M737, Dako, Germany, 1:50, $30 \mathrm{~min}$ ) and rabbit anti-mouse antibody (Z0259, Dako, 1:20, $30 \mathrm{~min}$ ) were diluted in Dako Chem Mate Antibody diluent (S2022). APAAP complexes (D0651, 1:50, $30 \mathrm{~min}$ ) were also obtained from Dako, Germany. Incubation with secondary antibody and APAAP complexes was repeated for $10 \mathrm{~min}$. Sections were washed with TBS between incubation steps. The alkaline phosphatase reaction was performed with neufuchsin (1:500, Merck, Germany) and naphthol-As-Bi-phosphate $(0.5 \mathrm{mg} / \mathrm{ml})$ (N-2250; Sigma). Levamisole $(0.4 \mathrm{mg} / \mathrm{ml}$; Sigma) was added to block endogenous alkaline phosphatase activity. In negative controls, the primary antibodies were omitted. Counterstaining was performed with hematoxylin (Merck, Germany). For staining of LAP (TGF- $\beta 1$ ), avidin-biotin complex staining was performed according to standard procedures. Briefly, endogenous peroxidase was blocked with $3 \%(\mathrm{v} / \mathrm{v})$ hydrogen peroxide ( $6 \mathrm{~min}$, room temperature) and unspecific binding sites were blocked by incubation with $10 \%(\mathrm{v} / \mathrm{v})$ rabbit non-immune serum (X0902, Dako, Germany, 30 min). Skin sections were incubated with anti-LAP (TGF- $\beta 1$ ) antibody (1:10, diluted in PBS) overnight. Secondary biotinylated rabbit anti-goat antibody (E466, Dako, Germany, $90 \mathrm{~min}$ ) was used 1:200 diluted in PBS containing 5\% (v/v) rabbit serum. Sections were washed with PBS between incubation 
steps. Color development was performed using avidinbiotinylated HRP complex (1:100), amino-ethyl-carbazole $(0.1 \mathrm{mg} / \mathrm{ml})$ and hydrogen peroxide $(0.015 \%, \mathrm{v} / \mathrm{v})$. Negative controls for the immunoreactions were performed with goat normal serum IgG or rabbit normal serum instead of primary antibody. Nuclei were counterstained with hematoxylin.

\section{Immunofluorescence}

Skin sections were deparaffinized and pre-treated with protease and elastase as described above. Cells $\left(7.5 \times 10^{4} / \mathrm{cm}^{2}\right)$ were cultured in 8-well chamber slides (Nunc, USA) for 5 days in the presence of $20 \%$ fetal calf serum, fixed with ice-cold $70 \%$ methanol $/ 30 \%$ aceton $(\mathrm{v} / \mathrm{v})$ for $5 \mathrm{~min}$, and incubated with $10 \%(\mathrm{v} / \mathrm{v})$ non-immune goat serum for $1 \mathrm{~h}$ to block non-specific binding sites. Skin sections or fixed cells were first incubated with the anti-tenascin-C antibody (1:200 diluted in PBS, $1 \mathrm{~h}$ ), and then with the anti-fibrillin-2 antibody (1:1000 diluted in PBS, $1 \mathrm{~h}$ ). Alexa Fluor 546 goat antimouse (1:400 diluted in PBS, red) and Alexa Fluor 488 goat anti-rabbit (1:400 diluted in PBS, green) were used as secondary antibodies ( $1 \mathrm{~h}$; Invitrogen, USA). Skin sections or multi wells were washed with PBS between incubation steps. Negative controls for the immunoreactions were performed with goat normal serum IgG or normal serum (mouse, rabbit) instead of primary antibody. For colocalization studies of fibrillin-2 and LAP (TGF- $\beta 1$ ), the protease step was omitted. Images were acquired with an Axioplan microscope, an AxioCam camera and processed using the Axiovision software version 4.6 (all Carl Zeiss Vision, Germany). Pearsson's correlation coefficient for colocalization was calculated using ImageJ (version 1.41) and the JACOP plugin. A value of one indicates a perfect colocalization between the two patterns of intensities whereas a value of 0 corresponds to no overlap. Regions of green-red colocalization were highlighted on the images as a white overlay mask using the colocalization plugin by Pierre Bourdoncle (http://rsbweb.nih.gov/ij/plugins/colocalization.html).

\section{Cell Culture}

Human dermal fibroblasts were cultured from skin explants obtained from surplus tissue from patients undergoing plastic surgery. The cells were propagated as monolayers in Dulbecco's modified Eagle's medium (DMEM, PAA Laboratories $\mathrm{GmbH}$, Germany) supplemented with $10 \%(\mathrm{v} / \mathrm{v})$ fetal calf serum, $0.25 \mathrm{mM}$ ascorbate, $2 \mathrm{mM}$ glutamate, $100 \mathrm{U} / \mathrm{ml}$ penicillin, and $100 \mu \mathrm{g} / \mathrm{ml}$ streptomycin. Cells were maintained at $37^{\circ} \mathrm{C}$ in a $5 \% \mathrm{CO}_{2}$ atmosphere. Fibroblasts were studied at passage $5-8$. The serum response was tested by culturing confluent fibroblasts without or with $10 \%$ serum for $72 \mathrm{~h}$. Recombinant human cytokines (Tebu, Germany) were added to the cells for $48 \mathrm{~h}$ in the presence of $10 \%$ serum in the following concentrations based on previous studies: interleukin-4 (IL-4): $5 \mathrm{ng} / \mathrm{ml}$, TGF- $\beta: 10 \mathrm{ng} / \mathrm{ml}^{24}$ To study hypoxic effects, the fibroblasts were cultured in $1 \% \mathrm{O}_{2}, 5 \%$
$\mathrm{CO}_{2}$ and $94 \% \mathrm{~N}_{2}$ in a hypoxia workstation ( InvivO $_{2}$, Ruskinn Technology, Leeds, UK) for $72 \mathrm{~h}$.

\section{Cell Attachment, Spreading and Proliferation Assays}

To quantify cell attachment properties of fibroblasts, 96-well plates (Maxisorp, Nunc) were coated with human tenascin-C (TG 6044, Millipore, USA), and the recombinant $\mathrm{N}$ - or C-terminal fragment of human fibrillin-2 ( $\mathrm{rFBN} 2-\mathrm{N}, \mathrm{rFBN} 2-$ $\mathrm{C})$. Production and purification of these recombinant fibrillin-2 fragments have been described in detail previously. ${ }^{22}$ For one set of experiments, the wells were coated with $100 \mu \mathrm{l}$ of either $\mathrm{rFBN} 2-\mathrm{N}(1.25 \mu \mathrm{g} / \mathrm{ml})$ or $\mathrm{rFBN} 2-\mathrm{C}$ $(5 \mu \mathrm{g} / \mathrm{ml})$ alone or together with tenascin-C $(1.67 \mu \mathrm{g} / \mathrm{ml}$ with rFBN2-N and $8 \mu \mathrm{g} / \mathrm{ml}$ with rFBN2-C) in TBS overnight at $4^{\circ} \mathrm{C}$. Non-specific binding sites were blocked with $200 \mu \mathrm{l} 1 \%$ (w/v) bovine serum albumin (Sigma) in TBS for $3 \mathrm{~h}$ at $20^{\circ} \mathrm{C}$. In a second set of experiments, wells were first coated with $100 \mu \mathrm{l}$ of $10 \mu \mathrm{g} / \mathrm{ml}$ tenascin-C in TBS overnight at $4^{\circ} \mathrm{C}$. After blocking non-specific binding sites with $1 \%(\mathrm{w} / \mathrm{v}) \mathrm{BSA}$ for $3 \mathrm{~h}, \mathrm{rFBN} 2-\mathrm{N}(30 \mu \mathrm{g} / \mathrm{ml})$ was added to some of the tenascin-C-coated wells for $2 \mathrm{~h}$ at $20^{\circ} \mathrm{C} .20000$ cells were added to each well and incubated for $2 \mathrm{~h}$ in DMEM at $37^{\circ} \mathrm{C}$. Non-attached cells were removed by washing three times with PBS. Attached cells were fixed with $1 \%(\mathrm{v} / \mathrm{v})$ glutaraldehyde in PBS and stained with $0.1 \%(\mathrm{w} / \mathrm{v})$ crystal violet for $25 \mathrm{~min}$. After extensive washing with $\mathrm{H}_{2} \mathrm{O}$, the dye was solubilized in Triton X-100, and quantified at $560 \mathrm{~nm}$ using an ELISA plate reader (EL-800, BioTec, USA). The number of attached cells was calculated using a standard of known cell numbers attached to gelatin-coated wells $(0.1 \%, 100 \mu \mathrm{l})$. Cell spreading was measured by counting spread cells on photographs $4 \mathrm{~h}$ after cell seeding using the ImageJ software. To determine proliferation, cells were maintained in serum-free fibroblast growth medium (PromoCell C23010, PromoCell, Germany) supplemented with $60 \mathrm{ng} / \mathrm{ml}$ PDGF. Cells were counted after 24,48 , and $72 \mathrm{~h}$ using a hexosaminidase assay as reported elsewhere. $^{25}$

\section{Cross-Link Analysis}

Skin specimens (about $20 \mathrm{mg}$ wet weight) were digested with high purity bacterial collagenase (C0773; Sigma, Germany; $1 \mathrm{U} / \mu \mathrm{l}, 37^{\circ} \mathrm{C}, 12 \mathrm{~h}$ ). After centrifugation, the residues were hydrolyzed in $6 \mathrm{~N} \mathrm{HCl}$ at $110^{\circ} \mathrm{C}$ for $24 \mathrm{~h}$. The hydrolyzate was pre-cleared on CF-11 cellulose columns to remove the bulk of non-cross linked amino acids. ${ }^{24}$ Dried eluates were redissolved in sodium citrate loading buffer ( $\mathrm{pH}$ 2.2) and analyzed on an amino acid analyzer (Biochrom 20, Biochrom, England) using a three buffer gradient system and post column ninhydrin derivatization. The column was eluted for $5 \mathrm{~min}$ (flow rate $15 \mathrm{ml} / \mathrm{h}$ ) with sodium citrate buffer $(\mathrm{pH}$ 4.25), for 40 min with sodium citrate buffer $(\mathrm{pH} 5.35)$ and for 20 min with sodium citrate/borate buffer $(\mathrm{pH}$ 8.6) at $80^{\circ} \mathrm{C}$. Retention times of isodesmosine and desmosine were established with an elastin standard (No. 20946, Serva, Germany). Quantification was based on ninhydrin-generated 
leucine equivalence factors using 3.4 for both isodesmosine and desmosine. ${ }^{26}$ Protein content in a sample was determined by amino acid analysis $(10 \mu \mathrm{l})$ taken from hydrolyzates before CF11-precleaning.

RNA Extraction and Real-Time Quantitative PCR Analysis RNA from skin specimens was extracted using the RNeasy Mini kit (Qiagen, Germany) and treated with RNase-free DNase I to remove potentially contaminating DNA. The RNA was subsequently reverse transcribed into cDNA with random hexamer primers using Superscript II (Invitrogen) according to the manufacturer's protocol. The primer pairs for fibrillin-2 (U03272; sense: 5' - AATCCTAGCACAGCCAG TCTGC-3', antisense: $5^{\prime}$-AACCACGGTTGCCTTTGAGC-3', product size: $183 \mathrm{bp}$ ), lysyl oxidase (NM002317; sense: 5'-TTGTGCGCTGTGACATTCG-3', antisense: $5^{\prime}$-TTCCCAC TTCAGAACACCAGG- $3^{\prime}$, product size: $127 \mathrm{bp}$ ), and L28 as house keeping gene (BC011582; sense: 5'-GTCGTGCGGA ACTGCT-3', reverse: 5'-TTGTAGCGGAAGGAATTGCG-3', product size: $101 \mathrm{bp}$ ) were designed using the program Primer Express (Applied Biosystems, USA). Aliquots of the cDNA were subjected to real-time PCR in the presence of 0.625 units of Hot Goldstar polymerase (Eurogentec, Belgium), $375 \mathrm{nM}$ of each primer, $250 \mu \mathrm{M}$ dNTP, $4 \mathrm{mM}$ $\mathrm{MgCl}_{2}, \quad 1: 66000$ diluted SYBR green (Eurogentec) and 1 -fold concentrated PCR buffer in a total volume of $20 \mu \mathrm{l}$. For fibrillin-2, $0.15 \mu \mathrm{l}$ DMSO were added. The reaction volume was incubated at $95^{\circ} \mathrm{C}$ for $10 \mathrm{~min}$ followed by 40 cycles of $95^{\circ} \mathrm{C}$ for $15 \mathrm{~s}$ and $60^{\circ} \mathrm{C}$ for $60 \mathrm{~s}$. Standard curves were obtained after amplification of $5 \times 10^{3}-5 \times 10^{7}$ copies of purified gene-specific standards, which were generated by insertion of the respective amplicons into pCR2.1TOPO vector (Invitrogen). The PCRs were performed using the Gene Amp 5700 sequence detection system (Applied Biosystems).

\section{Protein Interaction}

Solid-phase assay

Solid-phase-binding assays were performed as described previously in detail with minor modifications. ${ }^{22}$ In brief, $10 \mu \mathrm{g} / \mathrm{ml}(100 \mu \mathrm{l})$ of tenascin-C were immobilized in TBS for $16 \mathrm{~h}$ at $4^{\circ} \mathrm{C}$ in 96-well plates (Maxisorp; Nalge Nunc International) and blocked with $5 \%(\mathrm{w} / \mathrm{v})$ non-fat milk in TBS including $2 \mathrm{mM} \mathrm{CaCl}$. Washing after this and all following steps was performed with TBS including $2 \mathrm{mM}$ $\mathrm{CaCl}_{2}$ and $0.05 \%$ Tween 20. Serial dilutions (1:3) of fibrillin fragments in TBS including $2 \mathrm{mM} \mathrm{CaCl}_{2}$ and $2 \%(\mathrm{w} / \mathrm{v})$ nonfat milk (binding buffer) were incubated for $2 \mathrm{~h}$ at $22^{\circ} \mathrm{C}$ with the immobilized proteins. To detect bound ligands, the wells were incubated for $90 \mathrm{~min}$ with the respective polyclonal antisera (diluted 1:1000), anti-rFBN2-N, and anti-rFBN2-C, followed by a $90-\mathrm{min}$ incubation with horseradish peroxidase-conjugated goat anti-rabbit antibody (diluted 1:800) and the color reaction.

\section{Slot blot-overlay assay}

One milligram of tenascin- $\mathrm{C}$ was blotted onto a nitrocellulose membrane using a slot blot manifold (Schleicher\& Schuell, Germany). The membranes were then incubated with TBS containing 5\% (w/v) non-fat milk to block unspecific binding sites for $1 \mathrm{~h}$. The recombinant rFBN2-N fragment was added as a soluble ligand for $3 \mathrm{~h}$ in TBS containing $5 \%(\mathrm{w} / \mathrm{v})$ non-fat milk and $2 \mathrm{mM} \mathrm{CaCl}$ (binding buffer). Incubation of rFBN2-N to non-fat milk blotted alone onto membranes served as negative control. After washing three times with TBS, the membranes were incubated for $2 \mathrm{~h}$ with monoclonal antibody 16E12 (1:50) in binding buffer against the soluble ligand. ${ }^{27}$ The membranes were incubated for $2 \mathrm{~h}$ with horseradish peroxidase-conjugated goat-anti mouse antibodies (1:800 diluted in binding buffer) followed by detection with ECL (Amersham, USA) according to the protocol of the manufacturer. Densitometric scanning was performed using ImageJ (Version 1.41) after background subtraction.

\section{Statistical Analysis}

Statistical analysis was performed using the $U$-test according to Wilcoxon, Mann and Whitney and the Wilcoxon matched pairs signed rank test. $P$-values $<0.05$ were considered significant.

\section{RESULTS \\ Expression of Fibrillin-2 in Normal Skin, Wound Healing, LDS, and Scleroderma}

In normal skin, fibrillin-2 was only detected at the dermalepidermal junction (Figure 1a, solid arrows) and in vessel walls (Figure 1a, arrowheads). In healing wounds, a marked increase of the fibrillin-2 expression in the dermis was found (Figure 1d). There is a distinct boarder separating the area of high fibrillin-2 expression in the scar tissue from the almost absent fibrillin-2 expression in the adjacent normal tissue (solid arrows in Figure 1d). A similar expression pattern was documented for tenascin- $\mathrm{C}$ in normal and in scar tissue (Figure $1 \mathrm{c}$ and $\mathrm{f}$ ). In the skin from individuals with LDS, a high expression of fibrillin-2 was found throughout the dermis (Figure 1g). This expression pattern correlated with that found for tenascin-C (Figure 1i). Skin from patients with scleroderma showed an increase in the expression of both, fibrillin-2 and tenascin-C (Figure 1j, 1). In wound healing and sclerosis both fibrils and a more granular appearance were noted for fibrillin-2 and tenascin-C. Contrary to fibrillin-2 and tenascin- $\mathrm{C}$, different expression patterns were observed for fibrillin-1, which is expressed throughout the dermis in normal skin, in scar tissue, in LDS as well as in scleroderma tissue (Figure 1b, e, h, k). Typically, more diffuse fibrillin-1 staining with a more granular appearance was detected in scars and LDS tissues compared with normal skin. 


\section{Normal skin}
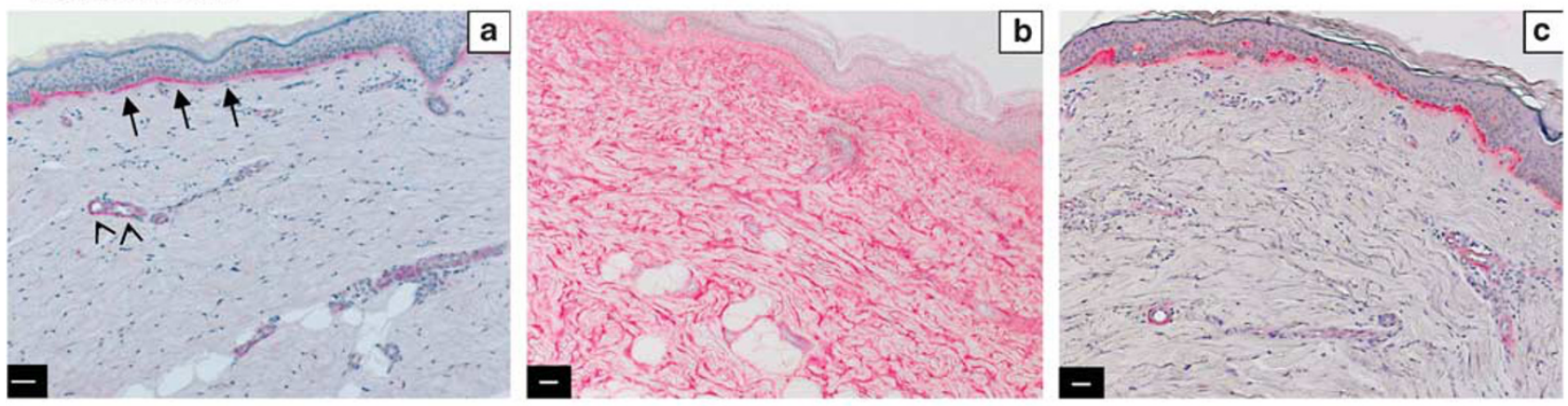

\section{Wound healing}
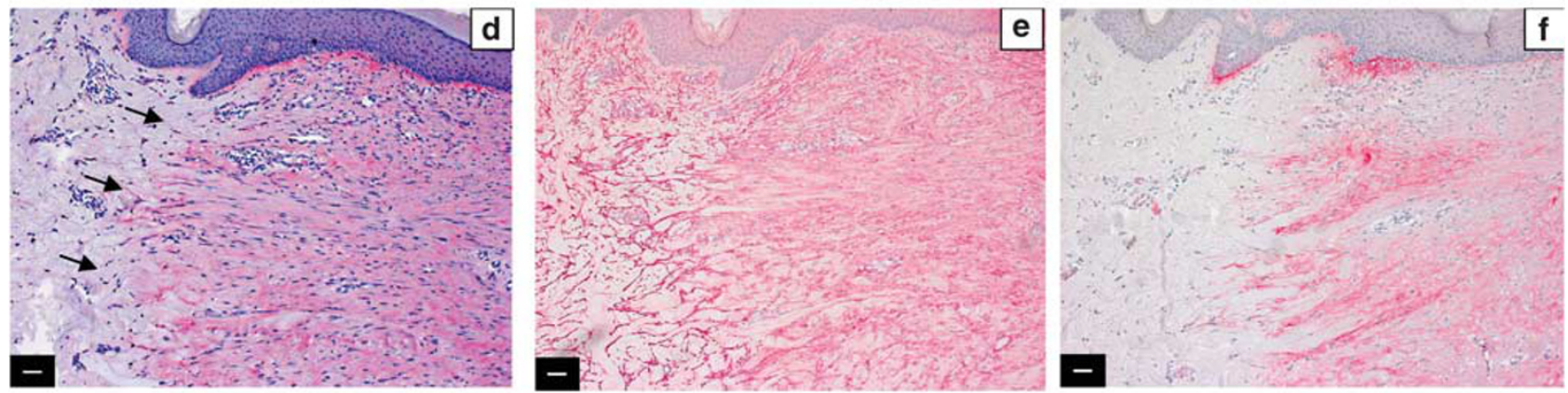

\section{LDS}
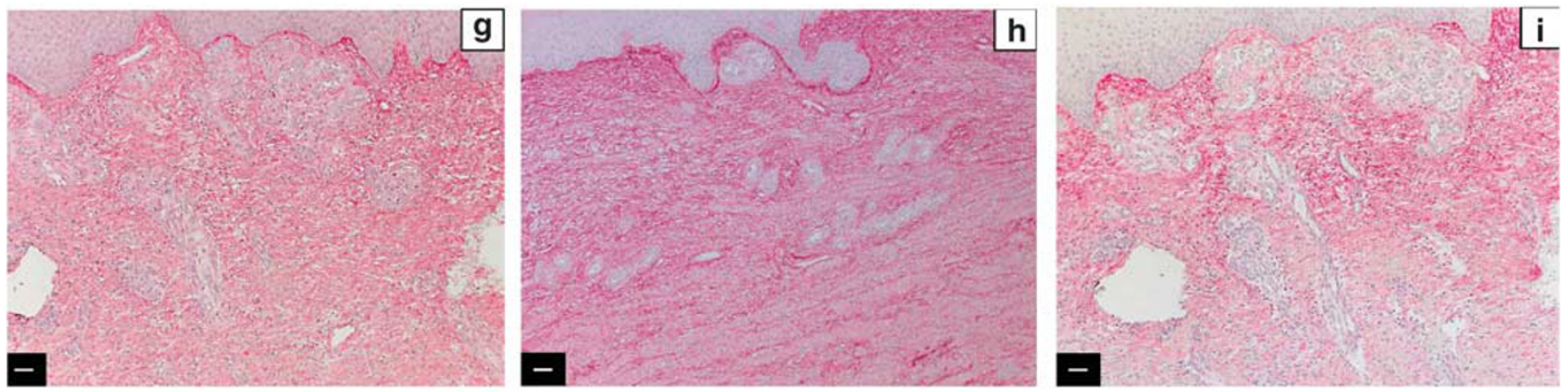

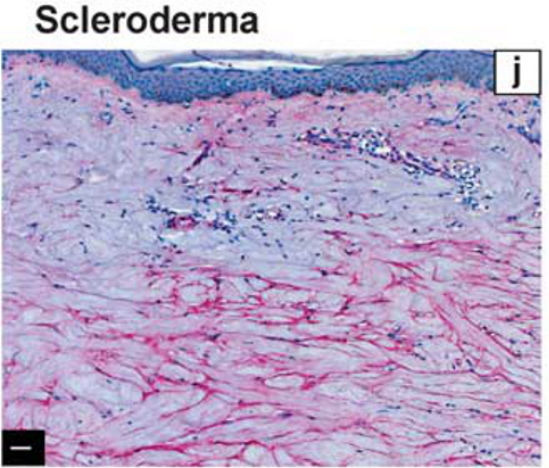

Fibrillin-2

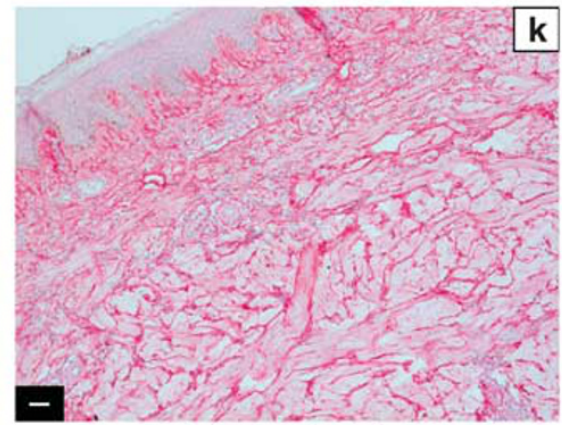

Fibrillin-1

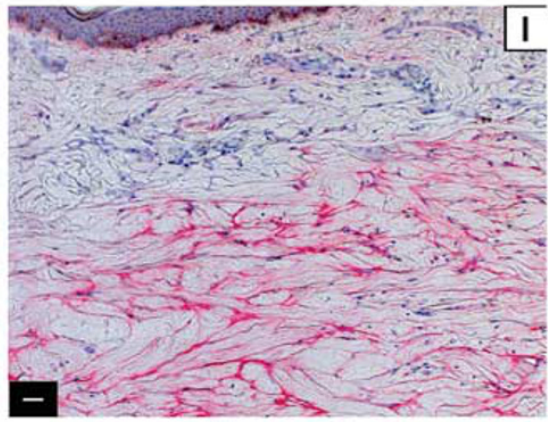

Tenascin C

Figure 1 Expression of fibrillins and tenascin-C in normal skin (a-c), healing wounds (d-f), LDS $(\mathbf{g}-\mathbf{i})$ and scleroderma (j-I). Skin sections were stained by APAAP and counter stained with hematoxylin. In normal skin (a), fibrillin-2 was found at the dermoepidermal junction (arrows) and in vessel walls

(arrowheads). In healing wounds (d), LDS (g) and scleroderma tissue (j), a marked increase of fibrillin-2 expression was observed. There is a distinct boarder separating the area of high fibrillin-2 expression in the scar tissue from the almost absent fibrillin-2 expression in the adjacent normal tissue (d, arrows). The pattern of tenascin-C in normal skin (c), wound healing (f), LDS (i), and scleroderma (I) is similar to that found for fibrillin 2. Fibrillin-1 is expressed in normal skin (b), wound healing (e), LDS (h), and scleroderma (k) throughout the dermis. In healing wounds and LDS tissue, fibrillin-1 fibrils were finer with a granular appearance. Scale bars are $50 \mu \mathrm{m}$ for all images. 


\section{Co-Distribution of Fibrillin-2 and Tenascin-C in Skin and in the Extracellular Matrix Synthesized in Cell Culture}

As the spatial expression pattern of tenascin-C and fibrillin-2 in immunohistochemistry was similar, double immunofluorescence was performed to test more directly whether fibrillin-2 and tenascin-C co-distribute. Overall, the expression patterns observed by immunofluorescence correlated well with those obtained by immunohistochemistry. Normal skin showed a relatively weak expression of both proteins, which showed a moderate colocalization $(r=0.50$, Figure 2a, row A). The relative intensity of fibrillin- 2 and tenascin-C staining varied in different regions excluding cross reactivity of the antibodies (Figure 2a, row A, arrowheads). No co-localization for fibrillin-1 and tenascin-C was observed $(r=0.03$, Figure $2 \mathrm{a}$, row $\mathrm{B})$. In wound tissue, co-localization of tenascin-C and fibrillin-2 as well as the previously described distinct difference of expression between scar tissue and healthy tissue was found $(r=0.64$, Figure $2 \mathrm{a}$, row C, arrowheads). The fibrillin-2 staining intensity of the healthy part of the skin was similar to that obtained for the negative control (not shown). Immunofluorescence of skin from LDS and scleroderma patients showed a marked co-distribution of fibrillin-2 and tenascin-C with a variation in staining intensity for LDS (LDS: $r=0.88$; scleroderma: $r=0.81$ Figure $2 \mathrm{~b}$, row $\mathrm{E}$ arrowheads and insert, row $\mathrm{G}$ ). In contrast to fibrillin-2, only minor co-localization was observed for fibrillin- 1 and tenascin- $\mathrm{C}$ in wound healing $(r=0.16$; Figure $2 \mathrm{a}$, row $\mathrm{D})$ and a moderate colocalization in scleroderma $(r=0.4$; Figure $2 \mathrm{~b}$, row $\mathrm{H})$ and LDS $(r=0.51$; Figure $2 \mathrm{~b}$, row F). Co-distribution of fibrillin-2 and tenascin-C was also tested in cell culture experiments (Figure 3). The extracellular matrix synthesized by human dermal fibroblasts cultured for 5 days was labelled with antibodies against fibrillin- 2 and tenascin- $\mathrm{C}$, which resulted in a co-staining pattern for both proteins $(r=0.8$; Figure 3$)$.

\section{Influence of Serum, IL-4, TGF- $\beta$, and Hypoxia on Fibrillin-2 Gene Expression}

Serum, IL-4, TGF- $\beta$, and hypoxia were shown to be important factors involved in the activation of fibroblasts and also increase the expression of tenascin-C. ${ }^{21,24,28,29}$ The effects of these factors on fibrillin-2 gene expression were tested by real-time PCR analysis. Starving of cells in the absence of serum resulted in a marked decrease of the gene expression level of fibrillin-2 of about $80 \%$ compared with cells cultivated in medium containing $10 \%$ serum. The addition of IL- 4 and TGF- $\beta$ resulted in a stimulation of the fibrillin-2 gene expression (IL-4: 2.2 fold; TGF- $\beta$ : 2.9 fold). In contrast, prolonged hypoxia in the presence of $1 \%$ oxygen did not significantly alter the steady state mRNA level of fibrillin-2 (Figure 4).

\section{Elastin Concentration}

Fibrillins have an important role in the biogenesis of elastic fibers. To answer the question, whether the increase of fibrillin-2 in sclerotic skin is associated with an increased deposition of mature elastin, we analyzed the elastin content in LDS by measuring the concentrations of the elastinspecific cross-links desmosine and isodesmosine generated by lysyl oxidases. The concentration of the total amount of isodesmosine and of desmosine per total protein content significantly decreased from $49.7( \pm 14.7) \mathrm{pmol} / \mu \mathrm{g}$ in normal skin to $19.8( \pm 28.2) \mathrm{pmol} / \mu \mathrm{g}(P<0.02)$ (Figure 5a). This decrease in cross-link formation is not caused by reduced lysyl oxidase gene expression, the rate limiting enzyme in elastin cross-link formation (Figure 5b). Real-time PCR with RNA extracted from sclerotic skin from LDS patients showed a threefold increase of the steady state mRNA level of lysyl oxidase.

\section{Cell Attachment, Spreading and Proliferation Assays and Protein Interaction}

Previously, it was shown that the interaction of tenascin-C with fibronectin resulted in a decrease of fibronectinmediated cell attachment. ${ }^{30}$ Therefore, we analyzed whether a potential interaction of tenascin- $\mathrm{C}$ and fibrillin-2 alters cell attachment properties of human skin fibroblasts. The N-terminal half of fibrillin-2 (rFBN2-N) contains both RGD sites, whereas the C-terminal half ( $\mathrm{rFBN2}-\mathrm{C}$ ) contains only one RGD site. ${ }^{22}$ Both RGD sites have been shown to be involved in integrin binding on the cell surface. ${ }^{4}$ First, we analyzed the dose dependency of the fibroblast's attachment to both recombinant halves of fibrillin-2. Coating concentrations of $1.25 \mu \mathrm{g} / \mathrm{ml}$ for $\mathrm{rFBN} 2-\mathrm{N}$ and $5 \mu \mathrm{g} / \mathrm{ml}$ for rFBN2-C lie within the linear portion of the cell attachment profiles and resulted in similar attachment efficacies (rFBN2N: $75 \pm 6 \%$ vs rFBN2-C: $67 \pm 7 \%, P>0.05)$. Therefore, these

Figure 2 Double immunofluorescence of tenascin-C and fibrillin-2 or fibrillin-1 of normal skin (a), wound healing (a), LDS (b) and scleroderma tissue (b). Skin sections were first stained with the anti-tenascin- $C$ antibody and then with the antibody against fibrillin-1 or fibrillin-2. Tenascin- $C$ is shown in red and fibrillin-1 or fibrillin-2 in green. In normal skin (a, row A), a co-distribution of tenascin-C with fibrillin-2 (white arrowhead) with a variation in staining intensity (green arrowhead for fibrillin-2, red arrowhead for tenascin-C) was observed. Similarly, in healing wounds (a, row C) and in scleroderma (b, row G), a codistribution of fibrillin-2 and tenascin- $C$ was noted. In a, row $C$, arrow heads indicate the boarder separating the area of high fibrillin- 2 expression in the scar tissue from the almost absent fibrillin-2 expression in the adjacent normal tissue. Immunofluorescence of LDS (b, row E) showed an almost complete colocalization of tenascin- $C$ and fibrillin-2 (white arrowhead) with a variation in staining intensity (row $E$ and insert; green arrowhead for fibrillin 2, red arrowhead for tenascin-C). For tenascin-C and fibrillin-1, no co-localisation was found in normal skin (a, row B) and minor co-localization in healing wounds (a, row D). The expression pattern partially overlapped in tissue of LDS (b, row F) or scleroderma patients (b, row G). Scale bars are $50 \mu \mathrm{m}$ for all images except inset $\mathbf{b}$, row $\mathbf{E}$, which is a $\times 2.8$ magnification of the small rectangle. Co-localized pixels are represented as a white overlay mask. 
concentrations were chosen for subsequent experiments. A mixed substratum of equimolar amounts of rFBN2-N and tenascin- $\mathrm{C}$ resulted in a significant decrease of cell attach- ment compared with the relative cell attachment to wells coated with rFBN2-N alone (Figure 6a). In contrast, coating of rFBN2-C together with equimolar amounts of tenascin-C a

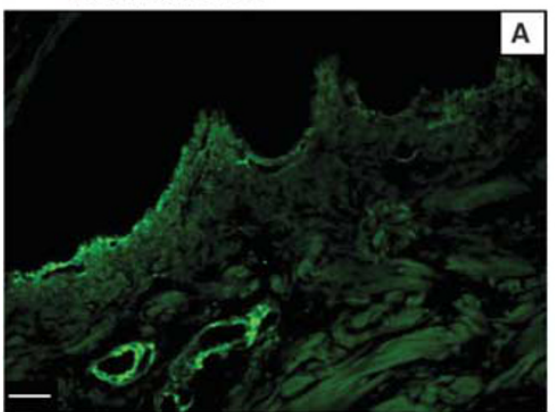

Fibrillin-2

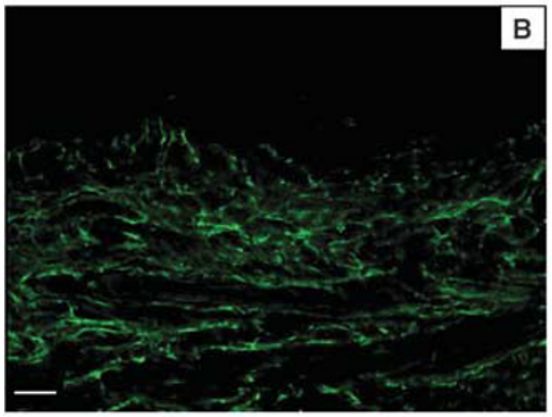

Fibrillin-1

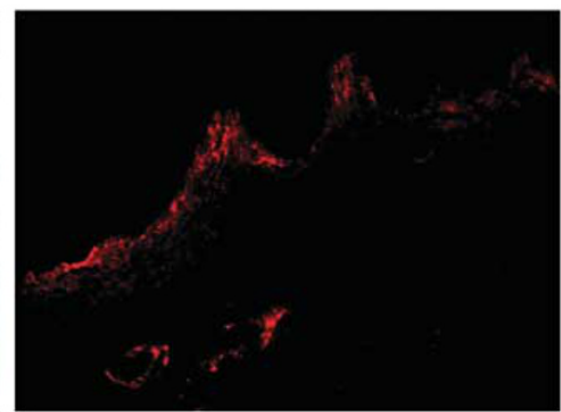

Tenascin C

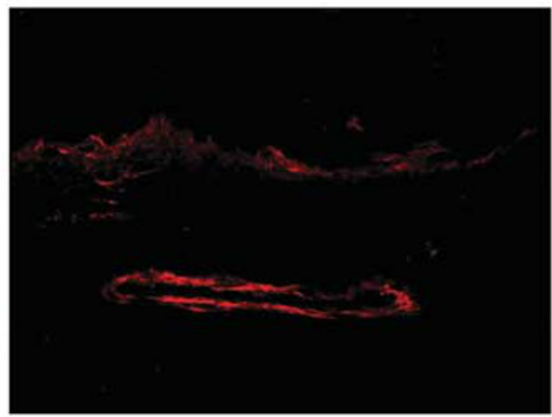

Tenascin C

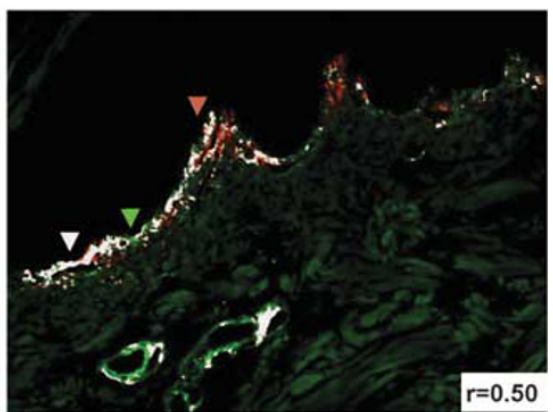

Colocalized pixels

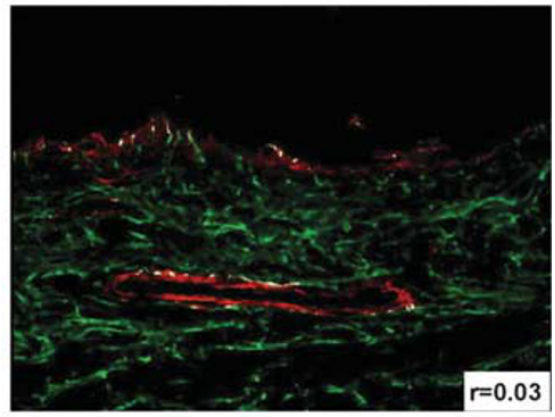

Colocalized pixels

\section{Wound healing}

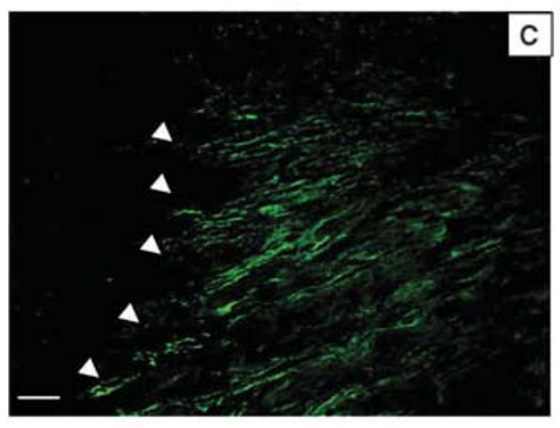

Fibrillin-2

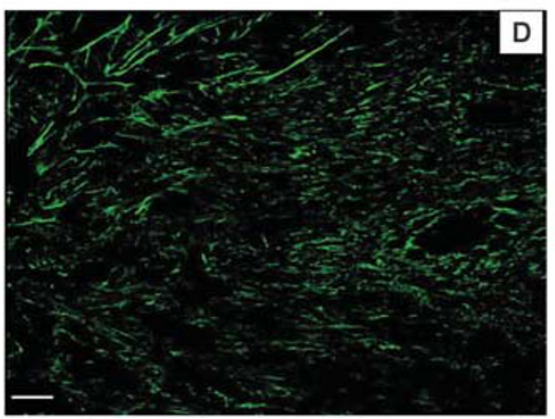

Fibrillin-1

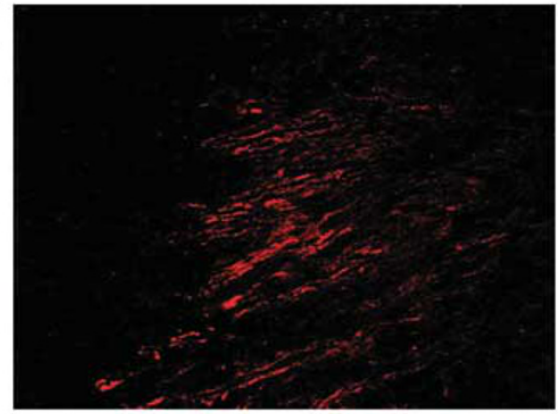

Tenascin C

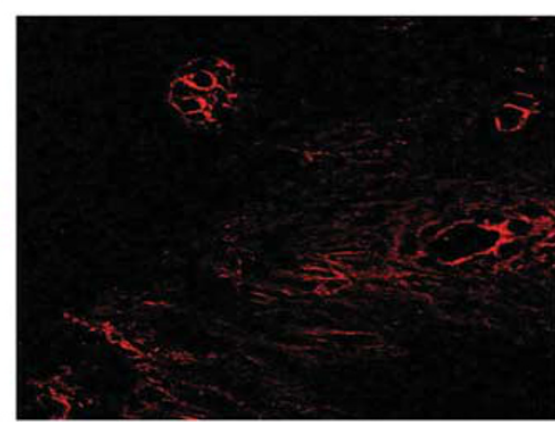

Tenascin C

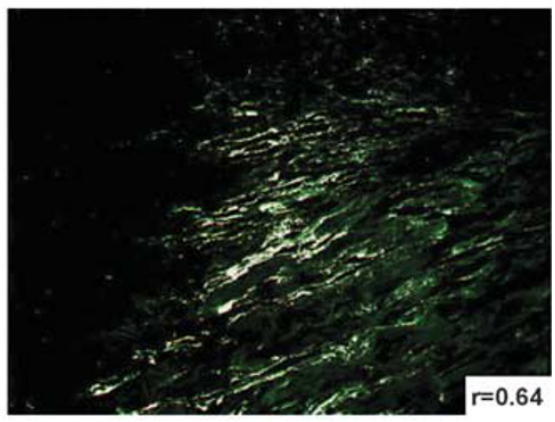

Colocalized pixels

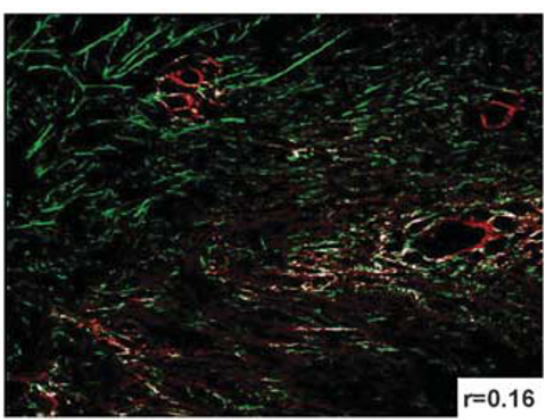

Colocalized pixels 


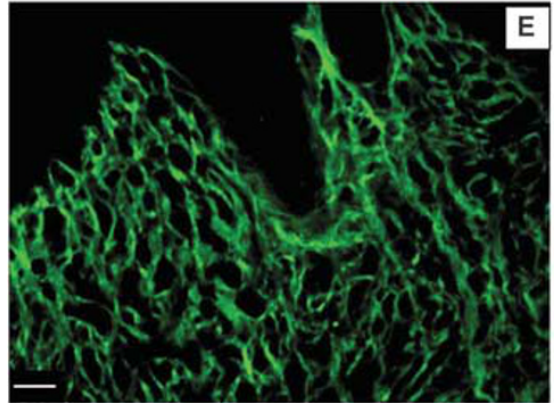

Fibrillin-2

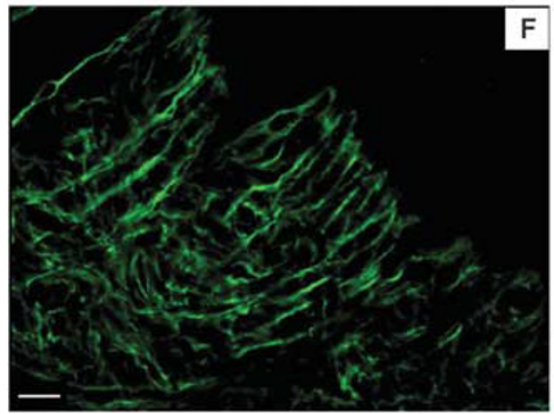

Fibrillin-1

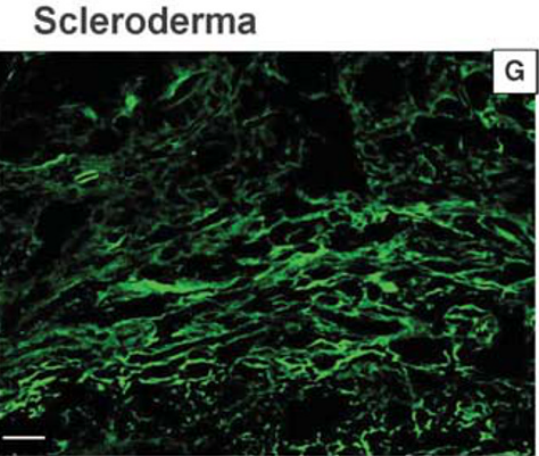

Fibrillin-2

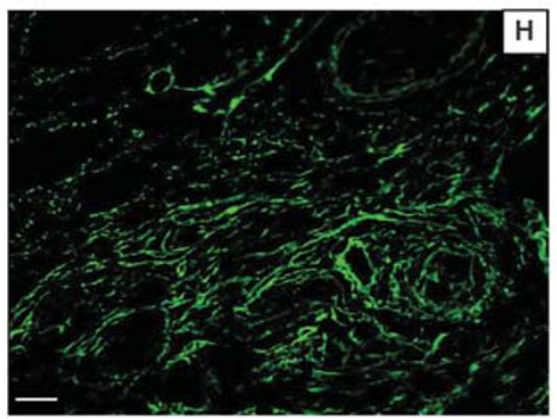

Fibrillin-1

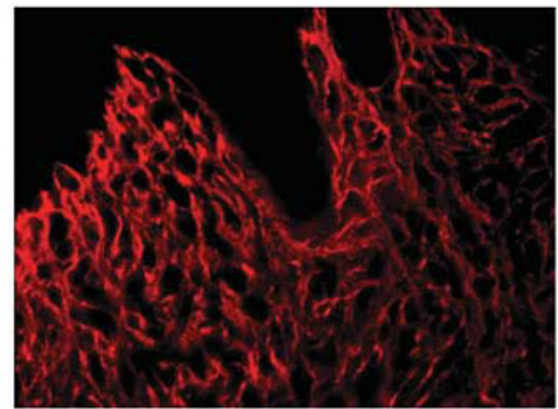

Tenascin C

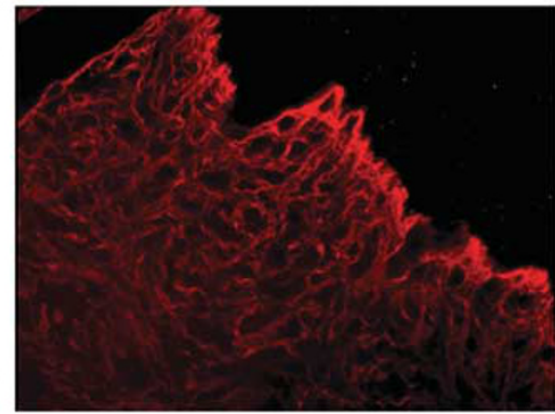

Tenascin C

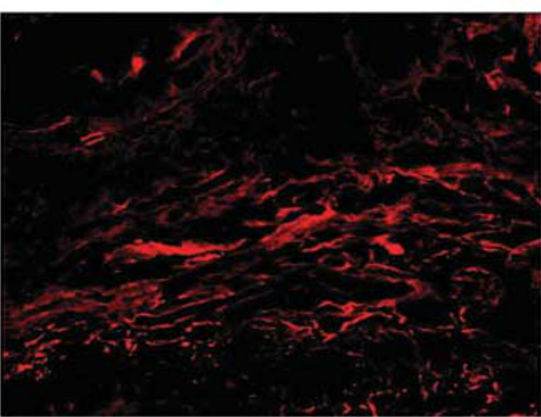

Tenascin C

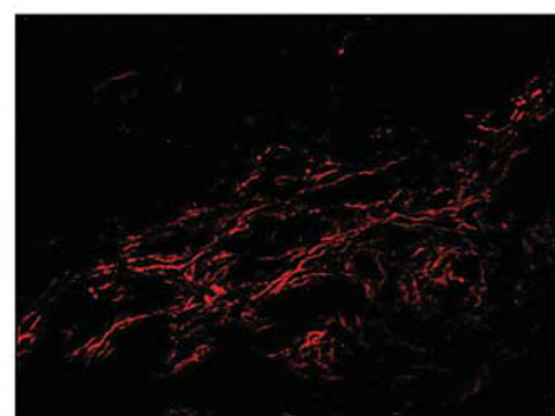

Tenascin C

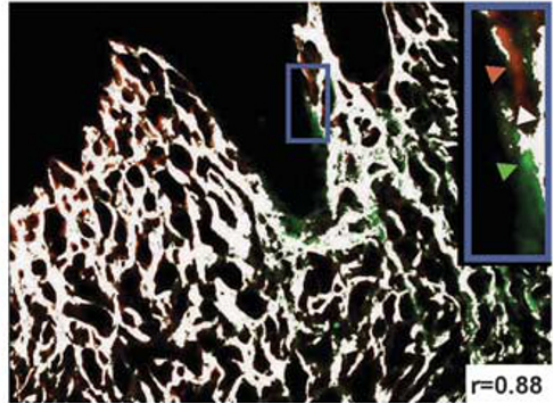

Colocalized pixels

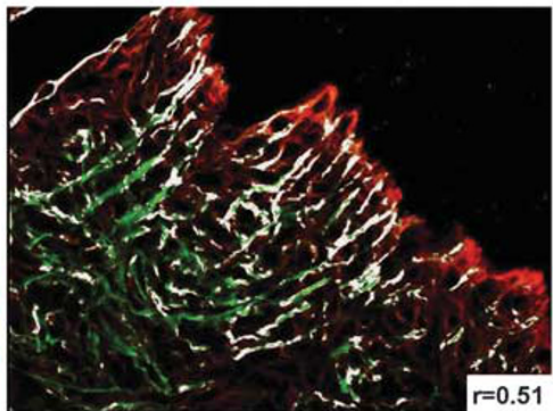

Colocalized pixels

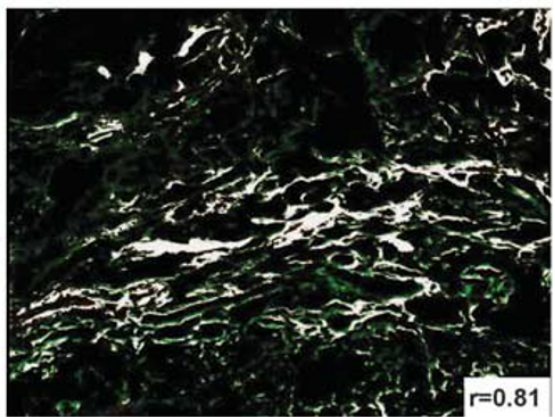

Colocalized pixels

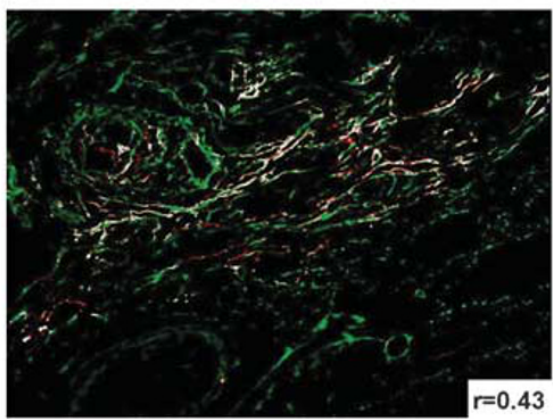

Colocalized pixels

Figure 2 Continued.

did not reduce cell adhesion of fibroblasts as compared with wells coated with rFBN2-C alone. We further analyzed whether potential binding of fibrillin- 2 to tenascin- $\mathrm{C}$ resulted in an increase in the cell attachment. Individual wells were first coated with tenascin- $\mathrm{C}$ and after blocking of nonspecific attachment sites with BSA, rFBN2-N was incubated 


\section{Cell culture}

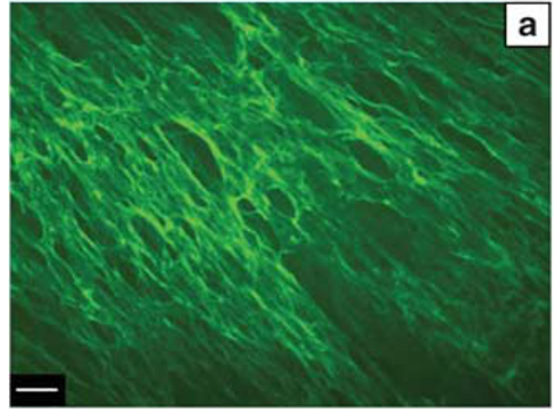

Fibrillin 2

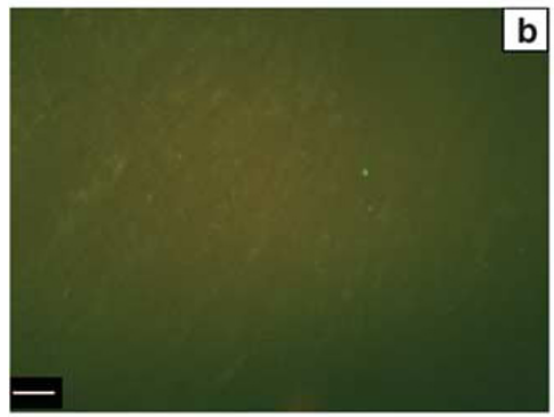

Negative control

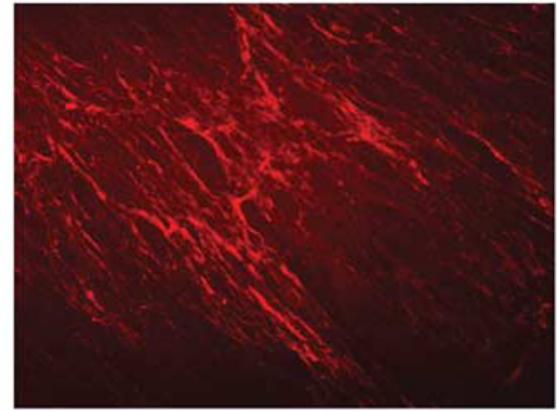

Tenascin C

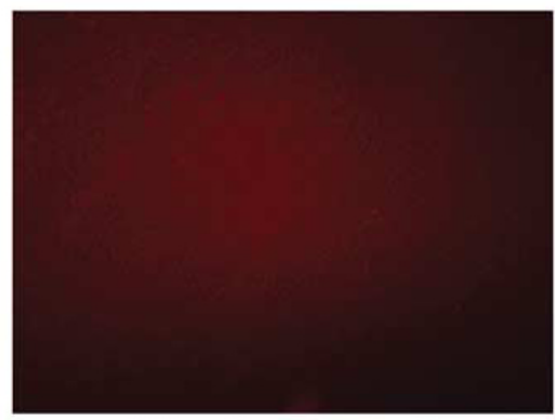

Negative control

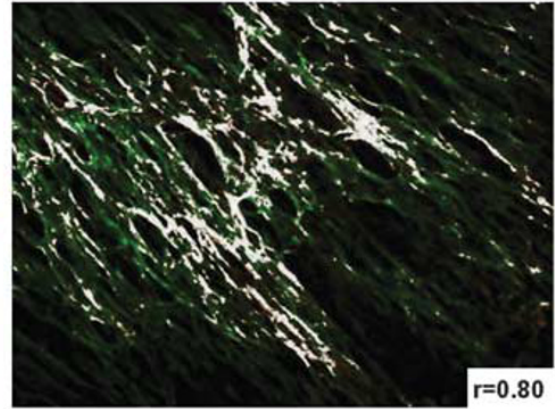

Colocalized pixels

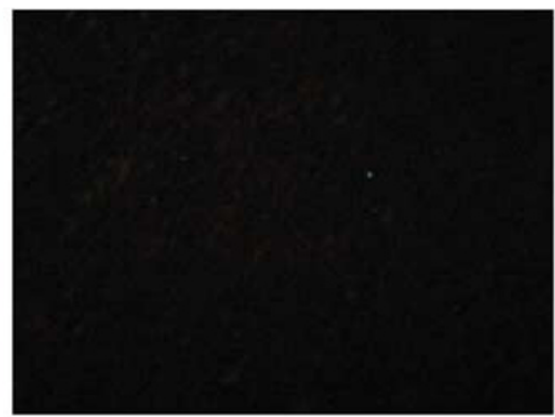

Colocalized pixels

Figure 3 Double immunofluorescence of tenascin- $C$ and fibrillin-2 of the extracellular matrix synthesized by cultured human dermal fibroblasts. Cells were cultured in multi-well chamber slides for 5 days. After fixation and blocking of non-specific binding sites, the cells were first incubated with the monoclonal anti-tenascin- $C$ antibody and then with the polyclonal anti-fibrillin- 2 antibody. (a) Tenascin- $C$ is shown in red and fibrillin- 2 in green. Both proteins significantly co-localized. (b) Negative control. Scale bars represent $50 \mu \mathrm{m}$. Co-localized pixels are represented as a white overlay mask.

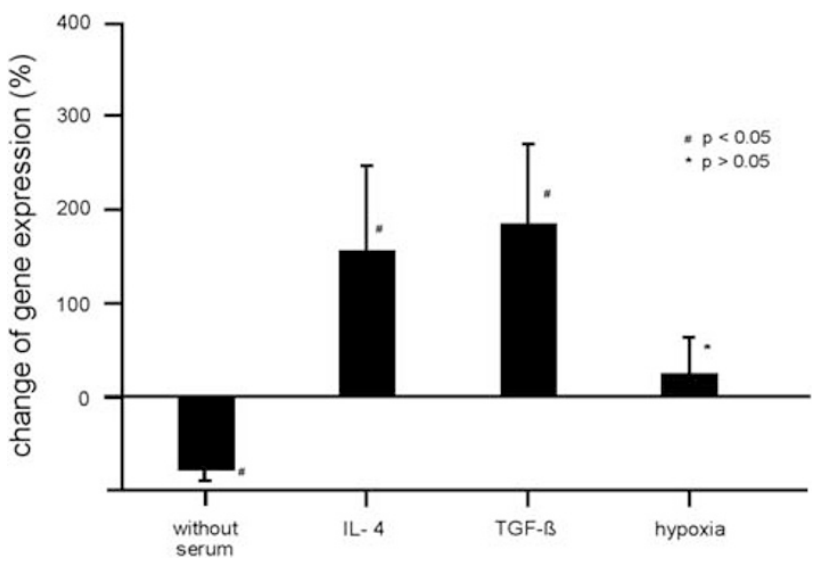

Figure 4 Influence of serum starving, TGF- $\beta$, IL-4, and hypoxia on fibrillin-2 gene expression levels. The serum response was tested by culturing confluent fibroblasts without or with $10 \%$ serum for $72 \mathrm{~h}$. TGF- $\beta(10 \mathrm{ng} / \mathrm{ml})$ and IL-4 $(5 \mathrm{ng} / \mathrm{ml})$ were added to confluent fibroblasts for $48 \mathrm{~h}$ in the presence of $10 \%$ serum. To generate hypoxic conditions, confluent fibroblasts were cultivated in an atmosphere of $1 \% \mathrm{O}_{2}, 5 \% \mathrm{CO}_{2}$ and $94 \% \mathrm{~N}_{2}$ for $72 \mathrm{~h}$. Gene expression levels of fibrillin- 2 and the $\mathrm{L} 28$ housekeeping gene were analyzed by quantitative real-time PCR. Depicted are the means \pm s.d.; TGF- $\beta$ and IL 4: $n=7$, hypoxia and serum response $n=6$. The gene expression is indicated as relative gene expression of fibrillin-2/L28 in relation with the respective control (without TGF- $\beta, \mathrm{IL}-4$, and serum or under normoxic conditions). with the pre-coated tenascin-C layer. The subsequent attachment assay showed that the binding of rFBN2-N to coated tenascin-C resulted in increased cell attachment (Figure 6b). Similarly, the sequential coating of tenascin-C and rFBN2-N resulted in an increase of cell spreading (Figure 6c). No differences were observed in cell proliferation up to $72 \mathrm{~h}$ (data not shown).

To further analyze the direct interaction of tenascin- $\mathrm{C}$ and fibrillin-2, a solid-phase-binding assay was performed with tenascin- $\mathrm{C}$ as an immobilized ligand and rFBN2-N or rFBN2-C as soluble ligands, a moderate dose-dependent interaction of tenascin-C with $\mathrm{rFBN} 2-\mathrm{N}$ was observed. No interaction could be documented for tenascin-C and rFBN2$\mathrm{C}$ (Figure 7a). The dose-dependent interaction of tenascin-C and the recombinant $\mathrm{N}$-terminal half of fibrillin-2 was additionally validated in a slot blot-overlay assay ( $7 \mathrm{~b}$ and $\mathrm{c})$.

\section{Immunohistochemistry for LAP (TGF- $\beta 1$ )}

Fibrillins are involved in storage and activation of TGF- $\beta$ s and BMPs. ${ }^{31}$ Immunohistology with an antibody against LAP (TGF- $\beta 1$ ) showed a remarkable increase in wound healing and sclerosis. In normal skin, a positive staining was only evident in the papillary dermis and in the vessel walls, similar to the fibrillin-2 expression in normal skin (Figure 8a). 

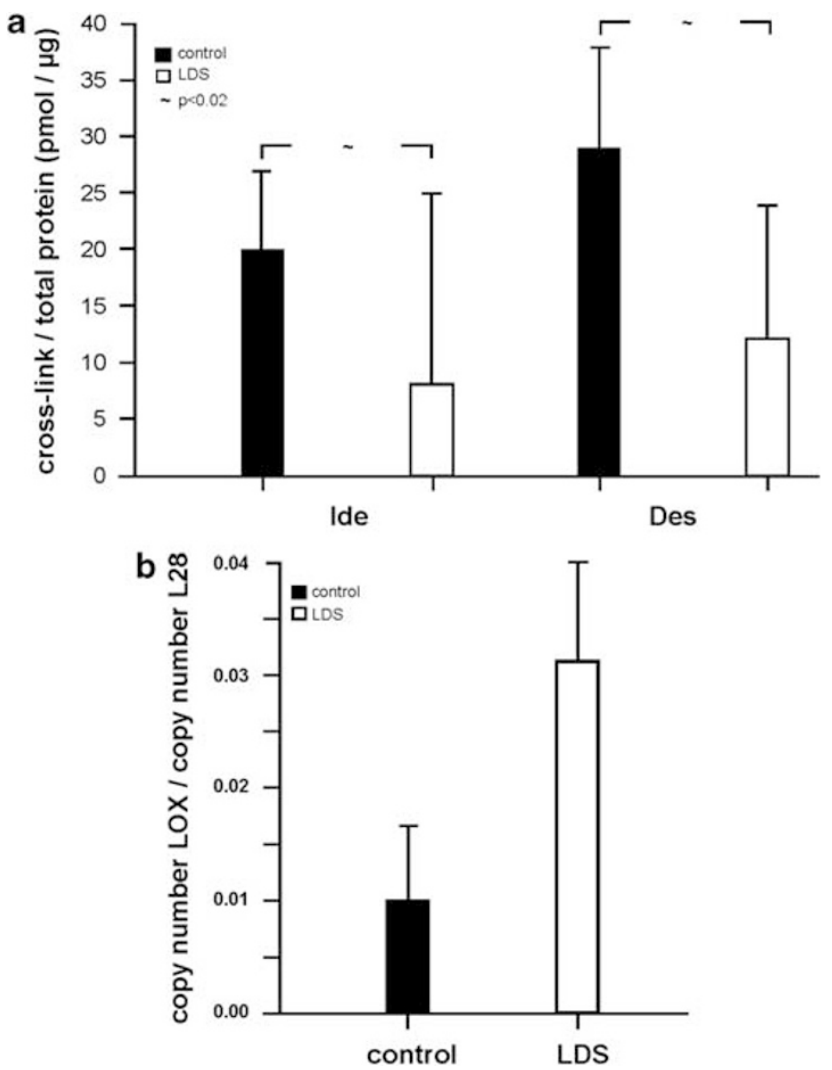

Figure 5 Elastin cross-link concentrations and gene expression level of lysyl oxidase in LDS tissue. (a) The isodesmosine (Ide) and desmosine (Des) content of collagenase-digested and hydrolyzed skin specimens was measured by amino acid analysis. Quantification was based on ninhydringenerated leucine equivalence factors and normalized to the total protein content. In sclerotic LDS skin (white bars) a decrease of the isodesmosine and desmosine content was observed as compared with healthy control skin (black bars). Depicted are the means \pm s.d.; normal skin: $n=7$, LDS: $n=14$. (b) Gene expression of lysyl oxidase in LDS tissue (white bar) vs control skin (black bar) was analyzed by quantitative real-time PCR and normalized to L28. Sclerotic skin specimens showed an increase of the lysyl oxidase gene expression level. Depicted are the means \pm s.d.; $n=3$.

In wound healing, LDS and scleroderma tissue, a higher expression of LAP (TGF- $\beta 1$ ) was noted, which appeared to be mainly cellular and pericellular (Figure 8b-d). Especially, in LDS tissue a similar expression pattern of fibrillin-2 and LAP (TGF- $\beta 1) \beta$ was found in some areas (Figure $8 \mathrm{e}, \mathrm{f}$ ). In immunofluorescence studies, a partial co-localization of both proteins was documented with a Pearson's correlation coefficient of 0.66 (Figure 8g-i).

\section{DISCUSSION}

Wound healing is characterized by an overlapping sequence of events comprising inflammation, cell proliferation, migration, differentiation, and tissue remodelling. These tightly regulated processes resemble in some aspects those found in embryonic development and also cause sclerosis when out of control. Especially, the composition of the extracellular matrix in wound healing and sclerosis shares many features
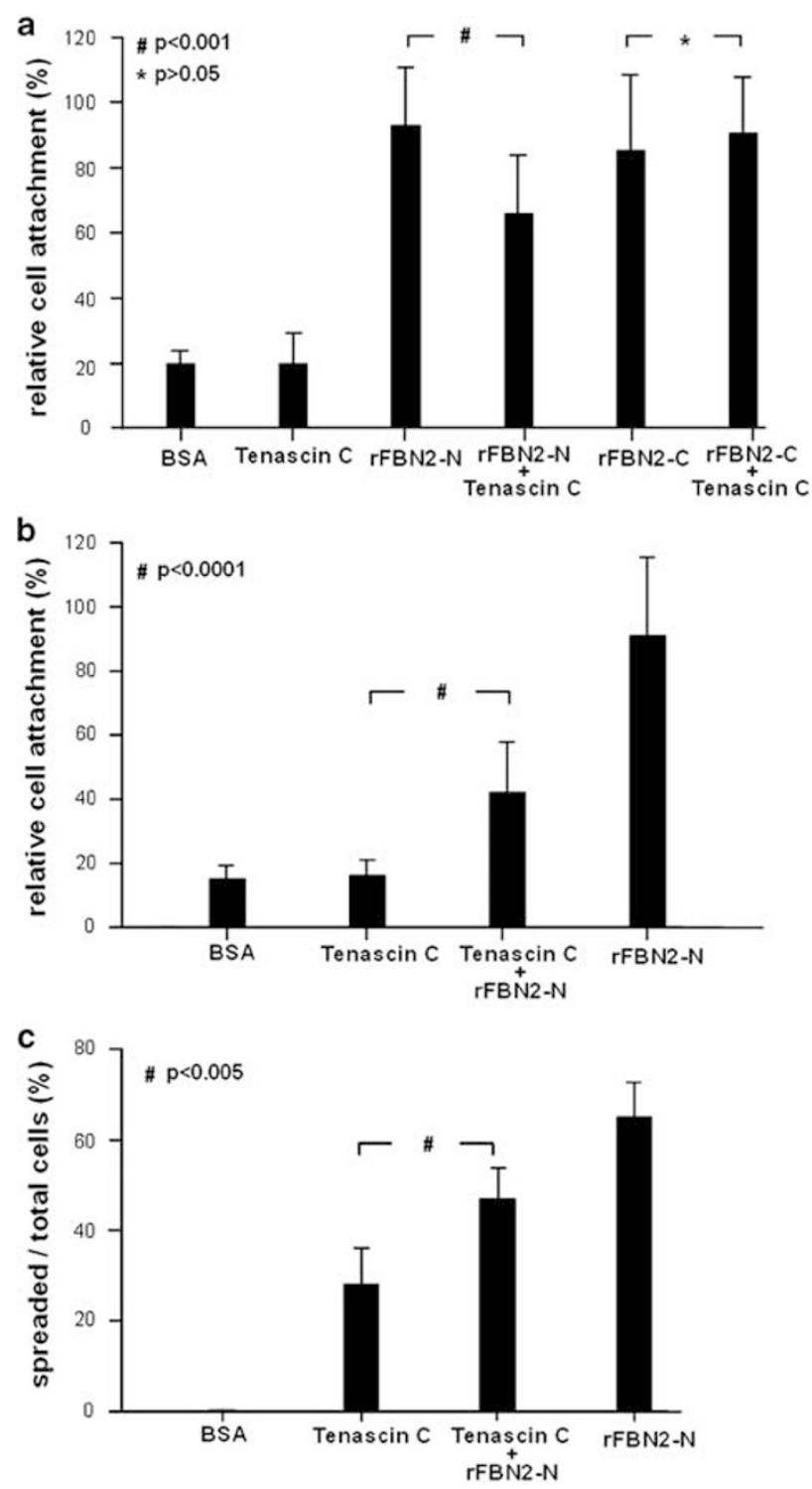

Figure 6 Attachment and spreading of human dermal fibroblasts to tenascin-C and fibrillin-2. (a) Wells were coated with rFBN2-N $(1.25 \mu \mathrm{g} / \mathrm{ml})$, rFBN2-C (5 $\mu \mathrm{g} / \mathrm{ml})$, or a mixed substratum of $1.25 \mu \mathrm{g} / \mathrm{ml} \mathrm{rFBN}-\mathrm{N}$ and $1.67 \mu \mathrm{g} /$ $\mathrm{ml}$ tenascin-C or $5 \mu \mathrm{g} / \mathrm{ml} \mathrm{rFBN}-\mathrm{C}$ and $8 \mu \mathrm{g} / \mathrm{ml}$ tenascin-C. 20000 cells were added for $2 \mathrm{~h}$ after blocking with $1 \% \mathrm{BSA}$. (b and $\mathbf{c}$ ) Wells were coated with tenascin-C $(10 \mu \mathrm{g})$ or rFBN-2-N $(10 \mu \mathrm{g})$. After blocking with 1\% BSA, rFBN-N $(30 \mu \mathrm{g})$ was added to some ( + rFBN2-N) of the tenascin-C coated wells for $3 \mathrm{~h}$. Cells attached after $2 \mathrm{~h}$ incubation were stained with crystal violet. The cell attachment is depicted as relative attachment in relation to 20000 cells attached to wells coated with $100 \mu \mathrm{l}$ of $0.1 \%$ gelatin. Depicted are the means \pm s.d.; $n=16$. For analysis of cell spreading, cells were photographed after $4 \mathrm{~h}$. Spread and total cells were counted using ImageJ $(n=5)$.

of an embryo-fetal matrix. This 'embryonic reprogramming' was shown for collagen and its modification, ${ }^{12,14,15,17,32,33}$ for adhesive glycoproteins, ${ }^{34-37}$ and for matricellular proteins. ${ }^{38}$

The data presented here show that the microfibrillar protein fibrillin-2, which is a typical component of embryonic skin but only scarcely expressed at the dermoepidermal junction in adult skin, is strongly re-expressed throughout the 

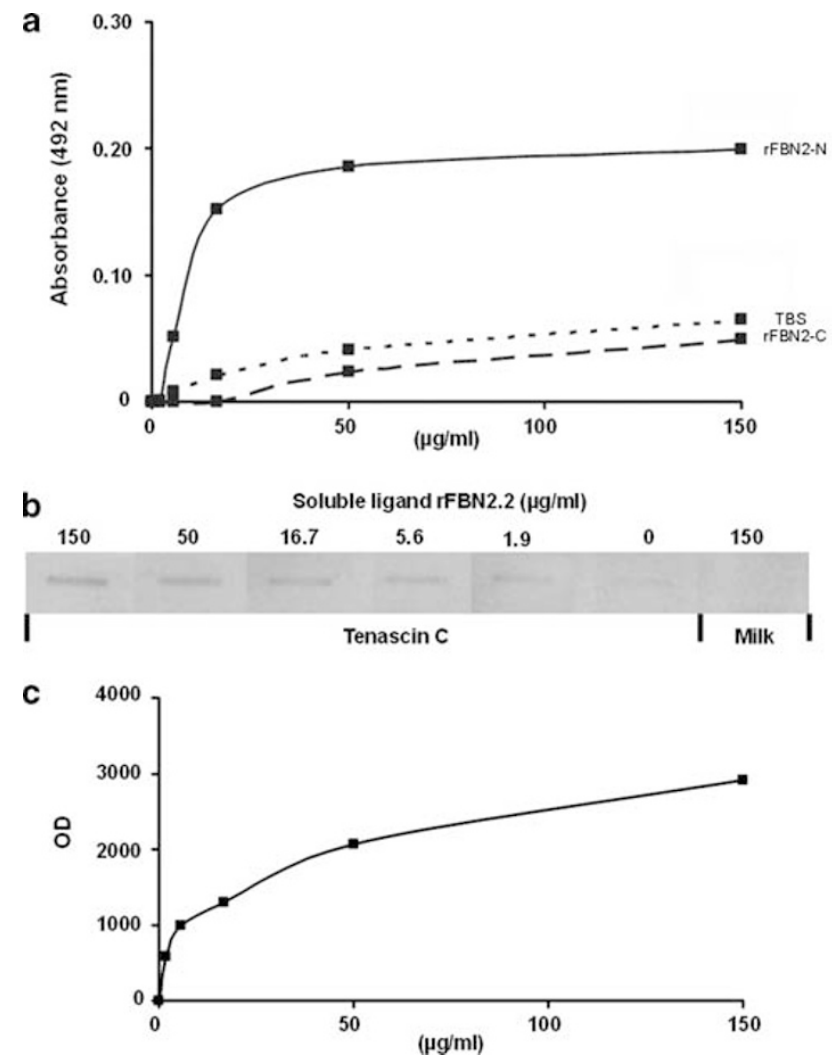

Figure 7 (a) Solid-phase assay. $1 \mu \mathrm{g} /$ well of tenascin C was immobilized on 96-well plates. Serial dilutions (1:3) of fibrillin fragments in TBS including $2 \mathrm{mM} \mathrm{CaCl} 2$ and $2 \%(\mathrm{w} / \mathrm{v})$ non-fat milk (binding buffer) were incubated with the immobilized proteins. Bound ligands were detected with the polyclonal antisera anti-rFBN2-N and anti-rFBN2-C (diluted 1:1000), followed by incubation with horseradish peroxidase-conjugated goat anti-rabbit antibody (diluted 1:800) and the color reaction. (b and c) Slot blot-overlay. (b) $1 \mu \mathrm{g}$ of tenascin- $\mathrm{C}$ was blotted onto a nitrocellulose membrane. The membrane was blocked with $5 \%(\mathrm{w} / \mathrm{v})$ non-fat milk in TBS. rFBN2-N was used in serial dilutions (1:3) starting from $150 \mu \mathrm{g} / \mathrm{ml}$ as a soluble ligand. Incubation of rFBN2-N $(150 \mu \mathrm{g} / \mathrm{ml})$ to non-fat milk blotted alone onto membranes served as negative control. Bound rFBN2-N was detected by specific antibodies as described in Materials and methods. (c) Densitometric analysis was performed using ImageJ after background subtraction. Plotted is the concentration of soluble rFBN2-N vs pixel intensities in arbitrary units.

dermis in wound healing and two examples of sclerotic skin diseases, LDS and scleroderma. Furthermore, we found increased fibrillin-2 expression in keloids and in lichen sclerosus et atrophicus, two additional examples of sclerotic skin diseases (data not shown). Our data are in line with results obtained with other fibrotic tissue: (i) Gene array analyses of scleroderma and lung fibrosis tissue showed increased fibrillin-2 gene expression levels. ${ }^{39,40}$ (ii) In pressure-induced kidney fibrosis, an increase of fibrillin-2 expression was shown by immunohistochemistry and western blotting. ${ }^{41}$ (iii) In a wound-healing study, using an antibody against both fibrillin isoforms, fibrillin was identified in the wound tissue. ${ }^{42}$ Fibroblasts in normal skin are thought to be in a quiescent state characterized by a low synthesis of extracellular matrix components. Under certain conditions, such as wound healing and sclerosis, or in cell culture after incubation with serum or inflammatory mediators, fibroblasts are activated and accumulate extracellular matrix proteins. ${ }^{28,43}$ We show here that the addition of typical mediators for fibroblast activation such as serum, TGF- $\beta$ and IL-4 to human dermal fibroblasts resulted in increased fibrillin-2 gene expression. Interestingly, prolonged hypoxia, which is typical for the chronic phase of sclerosis, was not accompanied by elevated fibrillin-2 gene expression. Correlating results were shown for the fibrillin-2 gene expression level in mesenchymal stem cells cultured under normoxic and hypoxic conditions. ${ }^{44}$ Thus, the accumulation of fibrillin-2 in wound healing and sclerosis appears to be an early event due to the contact of fibroblasts to serum or due to inflammation but is not sustained by hypoxia.

The spatial expression pattern of fibrillin-2 in normal skin, wound healing and sclerotic tissue resembles the pattern found for tenascin- $\mathrm{C}$, and in double-staining experiments fibrillin-2 and tenascin-C co-localized. The co-staining was specific, since the microfibrillar protein fibrillin-1 and tenascin-C showed very little co-distribution. Fibrillin-1 and -2 containing microfibrils are thought to have an important role in elastogenesis by providing a scaffold for the deposition of tropoelastin, which matures to elastin after cross-linking by lysyl oxidase and lysyl oxidase like protein $1 .{ }^{45}$ Our cross-link analysis of mature elastin in LDS showed that elevated fibrillin-2 expression was not accompanied by an increase of mature elastin. In fact, our data show a marked decrease of the mature elastin content in sclerotic skin from LDS patients, correlating with other published data for wound healing and scleroderma which show the presence of fibrillin-containing microfibrils without amorphous elastin in the lower dermis. ${ }^{15,46,47}$ The decrease in the mature elastin content was not caused by reduced lysyl oxidase gene expression, which was in fact three-fold increased as compared with normal skin. Changes in the concentration of elastin crosslinks may be caused by an altered gene expression level of elastin, a variation of elastin splice variants or changes in the degree of prolyl hydroxylation of elastin. ${ }^{48,49}$

Another potential consequence of increased fibrillin-2 expression in wound healing and fibrosis and of the co-localisation of fibrillin-2 and tenascin- $\mathrm{C}$ might be a change in the adhesion properties of the matrix for cells involved in wound healing. Fibrillin-2 has two RGD cell attachment sites located in the third and the fourth TB domain. Furthermore, fibrillin-2 has a heparin/heparan sulfate-binding site in the $\mathrm{N}$-terminal half of the protein, which might also be involved in cell attachment as it was shown for fibrillin-1., ${ }^{7,8}$ Our data show that the coating of a mixture of rFBN2-N and tenascin-C is accompanied by a decrease of cell attachment compared with coating of rFBN2-N alone. Interestingly, coating of a mixture of the C-terminal half of fibrillin-2, rFBN2-C, and tenascin-C did not alter the fibroblast cell attachment despite the presence of an RGD cell-binding site in rFBN2-C. This suggests that the presence of tenascin- $\mathrm{C}$ might modulate cell-binding properties, which are mediated through heparin/ 
Normal skin

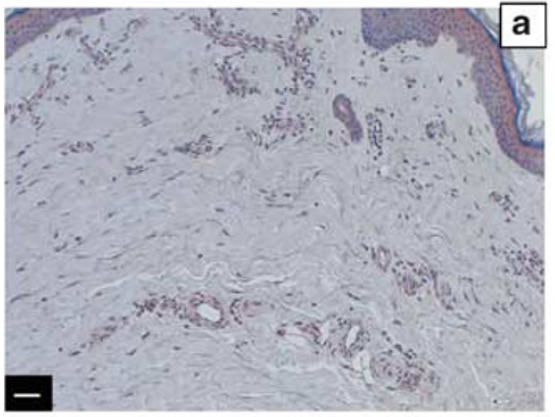

Scleroderma
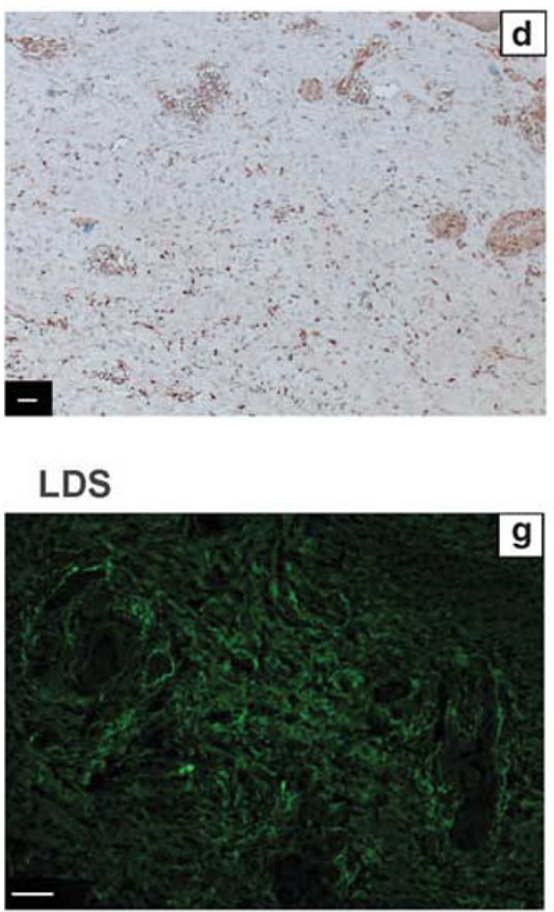

Fibrillin-2
Wound healing

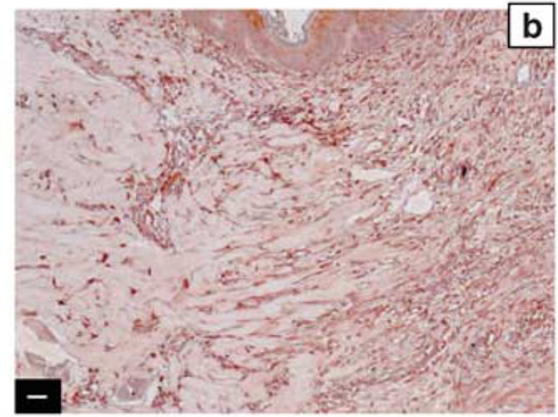

LDS
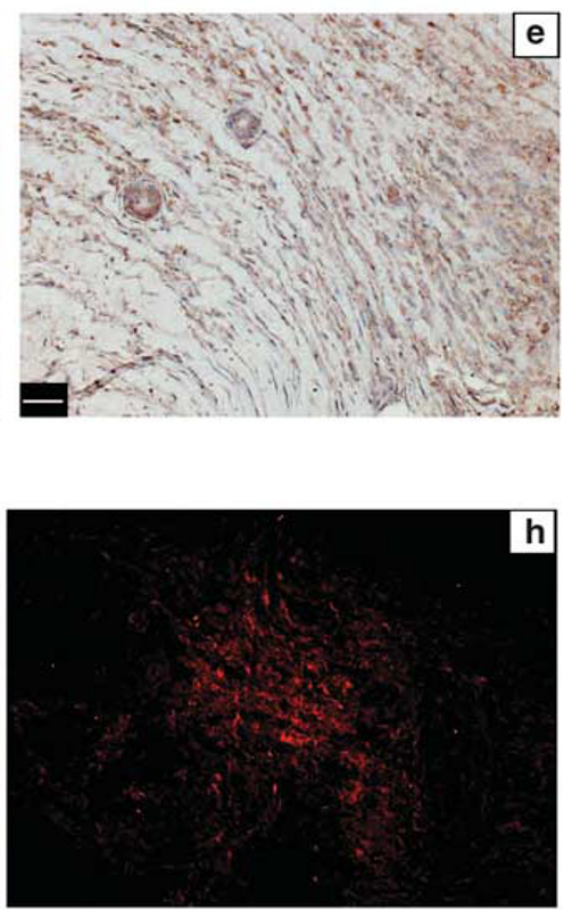

LAP (TGF- $\beta 1$ )
LDS

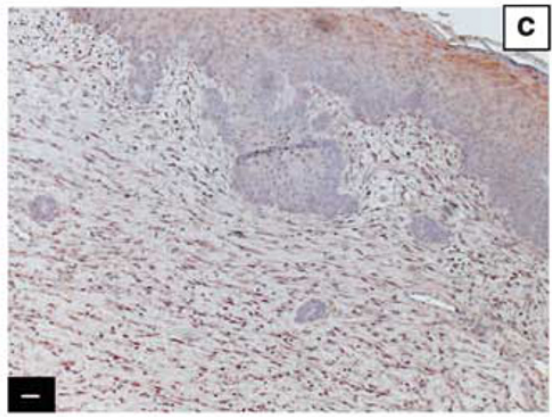

LDS Fibrillin 2
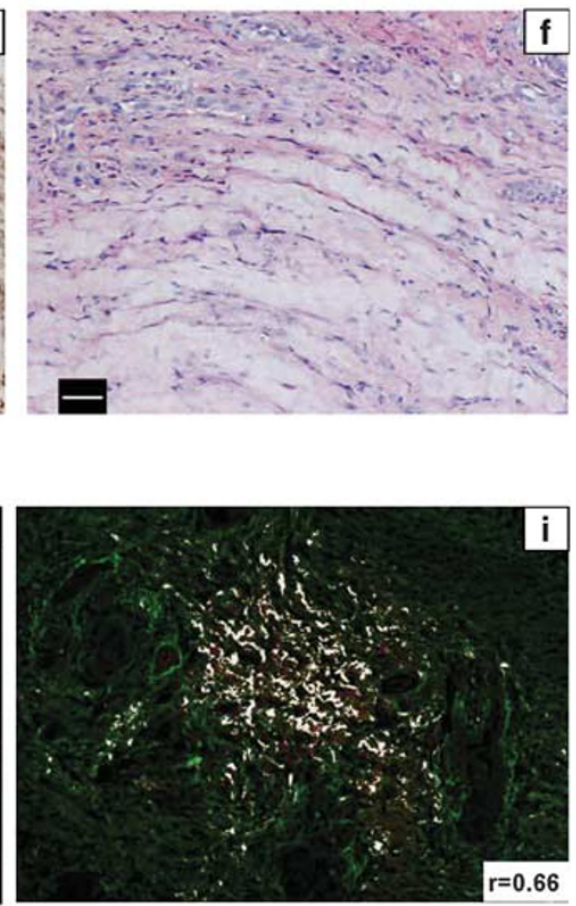

Colocalized pixels

Figure 8 Expression of LAP (TGF- $\beta 1$ ) in normal skin, wound healing, LDS, and scleroderma tissue and colocalization of LAP (TGF- $\beta 1$ ) and fibrillin-2. For staining of LAP (TGF- $\beta 1$ ), avidin-biotin complex staining was performed. Endogenous peroxidase was blocked with hydrogen peroxide and non-specific binding sites were blocked by incubation with rabbit serum. Color development was performed with amino-ethyl-carbazole and hydrogen peroxide. While normal skin (a) showed only a weak expression of LAP (TGF- $\beta 1$ ) in the papillary dermis, a marked increase of LAP (TGF- $\beta 1$ ) was found in healing wounds (b), LDS (c and e) and scleroderma tissue (d). Fibrillin-2 staining of LDS tissue (f) was included to depict the similar distribution pattern with LAP (TGF- $\beta 1$ ) in some areas. For double immunofluorescence of LAP (TGF- $\beta 1$ ) and fibrillin- 2 , skin sections were first stained with the anti-LAP (TGF- $\beta 1$ )-antibody over-night and then with the antibody against fibrillin-2. LAP (TGF- $\beta 1$ ) is shown in red (h) and fibrillin-2 in green (g). Scale bars represent $50 \mu$ m. Co-localized pixels are represented as a white overlay mask.

heparan sulfate binding sites or the RGD site located in the N-terminal half of fibrillin-2. ${ }^{4,7}$ This could modulate the properties of the tissue to facilitate the attachment of cells migrating in the wound area. A similar interaction affecting cell attachment was documented for tenascin-C and fibronectin. ${ }^{30,50}$ A solid-phase binding assay showed a moderate interaction of immobilized tenascin- $\mathrm{C}$ and the $\mathrm{N}$-terminal half of recombinant fibrillin-2 as a soluble ligand, whereas we could not detect a binding of tenascin- $\mathrm{C}$ and the $\mathrm{C}$-terminal half of fibrillin-2. The dose-dependent binding of the
N-terminal fibrillin-2 fragment to tenascin-C was also shown in a blot overlay-assay. An attachment assay by coating tenascin-C first and adding $r F B N 2-N$ as a soluble ligand showed an increase of cell binding and spreading compared with the attachment against tenascin- $\mathrm{C}$ alone.

Apart from the putative role of fibrillin-2 in elastogenesis and cell attachment, it is involved in matrix deposition, storage, and activation of growth factors of the TGF- $\beta$ superfamily. TGF- $\beta$ is synthesized as a pro-protein, bound to LAP. $^{51}$ This complex is secreted from cells bound to a 
member of the LTBP-family, which in turn interacts with fibrillin- 1 and $-2 .^{52}$ Furthermore, a direct interaction of the pro-peptides of BMP-2, $-4,-7$ and -10 to both, fibrillin- 1 and fibrillin-2, has been described recently. ${ }^{31}$ In our study, we show increased LAP (TGF- $\beta 1$ ) expression in wound healing and sclerosis as compared with normal skin, which correlated with a similar expression pattern of fibrillin-2 at least in some areas. A colocalization of both proteins was documented by double immunofluorescence. A recent report showed a reduced level of collagen cross-links in tendon of fibrillin-2deficient mice. ${ }^{53}$ Altered TGF- $\beta$ storage on fibrillin-2 containing microfibrils might be responsible for such changes as it was shown that TGF- $\beta$ influences the cross-linking pathway. ${ }^{54}$

In summary, our data show that the enhanced expression of fibrillin-2 is a general feature of activated fibroblasts found either in vivo in wound healing and sclerotic tissues or in cell culture after induction with serum, TGF- $\beta$ or IL- 4 . The elevated expression of fibrillin- 2 in wound healing and sclerotic tissue is another example for the 'embryonic reprogramming' of fibroblasts in these conditions.

\section{ACKNOWLEDGEMENTS}

We thank Dr Ruth Chiquet-Ehrismann, Friedrich Miescher Institute of Biomedical Research, Basel, Switzerland for supporting the study. We also thank Julia Fischer, Martina Alexander, Christine Fagotto-Kaufmann and Heiko Steenbock for excellent technical assistance. This work was supported by the Deutsche Forschungsgemeinschaft (Grants Br1146/3-1 and 3-3), the Deutsche Gesellschaft für Phlebologie, the Bundesministerium für Bildung und Forschung (German Network for Systemic Scleroderma), and the Canadian Institutes of Health Research (MOP-68836).

\section{DISCLOSURE/CONFLICT OF INTEREST}

The authors declare no conflict of interest.

1. Hubmacher D, Tiedemann K, Reinhardt DP. Fibrillins: from biogenesis of microfibrils to signaling functions. Curr Top Dev Biol 2006;75: 93-123.

2. Kielty $C M$, Baldock $C$, Lee $D$, et al. Fibrillin: from microfibril assembly to biomechanical function. Philos Trans R Soc Lond B Biol Sci 2002;357:207-217

3. Handford PA, Downing AK, Reinhardt DP, et al. Fibrillin: from domain structure to supramolecular assembly. Matrix Biol 2000;19:457-470.

4. Pfaff $M$, Reinhardt DP, Sakai LY, et al. Cell adhesion and integrin binding to recombinant human fibrillin-1. FEBS Lett 1996;384:247-250.

5. Sakamoto H, Broekelmann T, Cheresh DA, et al. Cell-type specific recognition of RGD- and non-RGD-containing cell binding domains in fibrillin-1. J Biol Chem 1996;271:4916-4922.

6. Bax DV, Bernard SE, Lomas A, et al. Cell adhesion to fibrillin-1 molecules and microfibrils is mediated by alpha 5 beta 1 and alpha $v$ beta 3 integrins. J Biol Chem 2003;278:34605-34616.

7. Ritty TM, Broekelmann TJ, Werneck CC, et al. Fibrillin-1 and -2 contain heparin-binding sites important for matrix deposition and that support cell attachment. Biochem J 2003;375(Part 2):425-432.

8. Cain SA, Baldwin AK, Mahalingam Y, et al. Heparan Sulfate Regulates Fibrillin-1 N- and C-terminal Interactions. J Biol Chem 2008;283: 27017-27027.

9. Robinson PN, rteaga-Solis E, Baldock C, et al. The molecular genetics of Marfan syndrome and related disorders. J Med Genet 2006;43:769-787.

10. Quondamatteo F, Reinhardt DP, Charbonneau NL, et al. Fibrillin-1 and fibrillin-2 in human embryonic and early fetal development. Matrix Biol 2002;21:637-646.
11. Corson GM, Charbonneau NL, Keene DR, et al. Differential expression of fibrillin-3 adds to microfibril variety in human and avian, but not rodent, connective tissues. Genomics 2004:83:461-472.

12. Smith LT, Holbrook KA, Madri JA. Collagen types I, III, and V in human embryonic and fetal skin. Am J Anat 1986;175:507-521.

13. Barnes MJ, Morton LF, Bennett RC, et al. Presence of type III collagen in guinea-pig dermal scar. Biochem J 1976;157:263-266.

14. Frances $C$, Branchet $M C$, Bletry $O$, et al. Skin collagen from scleroderma patients before and after cyclosporin A treatment. Clin Exp Dermatol 1988:13:1-3.

15. Robins SP, Milne G, Duncan A, et al. Increased skin collagen extractability and proportions of collagen type III are not normalized after 6 months healing of human excisional wounds. J Invest Dermatol 2003;121:267-272.

16. Bailey AJ, Bazin S, Sims TJ, et al. Characterization of the collagen of human hypertrophic and normal scars. Biochim Biophys Acta 1975;405:412-421.

17. Brinckmann J, Neess CM, Gaber $Y$, et al. Different pattern of collagen cross-links in two sclerotic skin diseases: lipodermatosclerosis and circumscribed scleroderma. J Invest Dermatol 2001;117:269-273.

18. Hinz B. Formation and function of the myofibroblast during tissue repair. J Invest Dermatol 2007;127:526-537.

19. White ES, Baralle FE, Muro AF. New insights into form and function of fibronectin splice variants. J Pathol 2008;216:1-14.

20. Jones FS, Jones PL. The tenascin family of ECM glycoproteins: structure, function, and regulation during embryonic development and tissue remodeling. Dev Dyn 2000;218:235-259.

21. Chiquet-Ehrismann R, Chiquet M. Tenascins: regulation and putative functions during pathological stress. J Pathol 2003;200:488-499.

22. Lin G, Tiedemann K, Vollbrandt T, et al. Homo- and heterotypic fibrillin-1 and -2 interactions constitute the basis for the assembly of microfibrils. J Biol Chem 2002;277:50795-50804.

23. Tiedemann K, Batge B, Muller PK, et al. Interactions of fibrillin-1 with heparin/heparan sulfate, implications for microfibrillar assembly. J Biol Chem 2001;276:36035-36042.

24. Brinckmann J, Kim S, Wu J, et al. Interleukin 4 and prolonged hypoxia induce a higher gene expression of lysyl hydroxylase 2 and an altered cross-link pattern: important pathogenetic steps in early and late stage of systemic scleroderma? Matrix Biol 2005;24: 459-468.

25. Puschel HU, Chang J, Muller PK, et al. Attachment of intrinsically and extrinsically aged fibroblasts on collagen and fibronectin. J Photochem Photobiol B 1995;27:39-46.

26. Sims TJ, Avery NC, Bailey AJ. Quantitative determination of collagen crosslinks. Methods Mol Biol 2000;139:11-26.

27. Hanssen E, Hew FH, Moore E, et al. MAGP-2 has multiple binding regions on fibrillins and has covalent periodic association with fibrillin-containing microfibrils. J Biol Chem 2004;279:29185-29194.

28. Wynn TA. Common and unique mechanisms regulate fibrosis in various fibroproliferative diseases. J Clin Invest 2007;117:524-529.

29. Gebb SA, Fox K, Vaughn J, et al. Fetal oxygen tension promotes tenascin-C-dependent lung branching morphogenesis. Dev Dyn 2005;234:1-10.

30. Huang W, Chiquet-Ehrismann R, Moyano JV, et al. Interference of tenascin- $C$ with syndecan- 4 binding to fibronectin blocks cell adhesion and stimulates tumor cell proliferation. Cancer Res 2001;61:8586-8594.

31. Sengle G, Charbonneau NL, Ono RN, et al. Targeting of bone morphogenetic protein growth factor complexes to fibrillin. J Biol Chem 2008;283:13874-13888.

32. Bailey AJ, Paul RG, Knott L. Mechanisms of maturation and ageing of collagen. Mech Ageing Dev 1998;106:1-56.

33. van der Slot AJ, Zuurmond AM, van den Bogaerdt AJ, et al. Increased formation of pyridinoline cross-links due to higher telopeptide lysyl hydroxylase levels is a general fibrotic phenomenon. Matrix Biol 2004:23:251-257.

34. Singh $\mathrm{P}$, Reimer $\mathrm{CL}$, Peters $\mathrm{JH}$, et al. The spatial and temporal expression patterns of integrin alpha9beta 1 and one of its ligands, the EIIIA segment of fibronectin, in cutaneous wound healing. J Invest Dermatol 2004;123:1176-1181.

35. Lightner VA, Gumkowski F, Bigner DD, et al. Tenascin/hexabrachion in human skin: biochemical identification and localization by light and electron microscopy. J Cell Biol 1989;108:2483-2493. 
36. Fassler R, Sasaki T, Timpl R, et al. Differential regulation of fibulin, tenascin- $C$, and nidogen expression during wound healing of normal and glucocorticoid-treated mice. Exp Cell Res 1996;222: $111-116$.

37. van der Straaten HM, Canninga-van Dijk MR, Verdonck LF, et al. Extra-domain-A fibronectin: a new marker of fibrosis in cutaneous graft-versus-host disease. J Invest Dermatol 2004;123:1057-1062.

38. Mori R, Shaw TJ, Martin P. Molecular mechanisms linking wound inflammation and fibrosis: knockdown of osteopontin leads to rapid repair and reduced scarring. J Exp Med 2008;205:43-51.

39. Gardner $H$, Shearstone JR, Bandaru R, et al. Gene profiling of scleroderma skin reveals robust signatures of disease that are imperfectly reflected in the transcript profiles of explanted fibroblasts. Arthritis Rheum 2006:54:1961-1973.

40. Selman M, Pardo A, Kaminski N. Idiopathic pulmonary fibrosis: aberrant recapitulation of developmental programs? PLoS Med 2008;5:e62.

41. Schaefer L, Mihalik D, Babelova A, et al. Regulation of fibrillin-1 by biglycan and decorin is important for tissue preservation in the kidney during pressure-induced injury. Am J Pathol 2004;165:383-396.

42. Ashcroft GS, Kielty CM, Horan MA, et al. Age-related changes in the temporal and spatial distributions of fibrillin and elastin mRNAs and proteins in acute cutaneous wounds of healthy humans. J Pathol 1997;183:80-89.

43. Chang HY, Sneddon JB, Alizadeh AA, et al. Gene expression signature of fibroblast serum response predicts human cancer progression: similarities between tumors and wounds. PLoS Biol 2004;2:E7.

44. Ohnishi S, Yasuda T, Kitamura S, et al. Effect of hypoxia on gene expression of bone marrow-derived mesenchymal stem cells and mononuclear cells. Stem Cells 2007;25:1166-1177.
45. Lucero HA, Kagan HM. Lysyl oxidase: an oxidative enzyme and effector of cell function. Cell Mol Life Sci 2006;63:2304-2316.

46. Fleischmajer $\mathrm{R}$, Jacobs $\mathrm{L}$, Schwartz $\mathrm{E}$, et al. Extracellular microfibrils are increased in localized and systemic scleroderma skin. Lab Invest 1991;64:791-798.

47. Davis EC, Blattel SA, Mecham RP. Remodeling of elastic fiber components in scleroderma skin. Connect Tissue Res 1999;40: 113-121.

48. Sato $F$, Wachi $H$, Ishida $M$, et al. Distinct steps of cross-linking, self-association, and maturation of tropoelastin are necessary for elastic fiber formation. J Mol Biol 2007;369:841-851.

49. Barone LM, Faris B, Chipman SD, et al. Alteration of the extracellular matrix of smooth muscle cells by ascorbate treatment. Biochim Biophys Acta 1985;840:245-254.

50. Chiquet-Ehrismann $R$, Kalla $P$, Pearson $C A$, et al. Tenascin interferes with fibronectin action. Cell 1988;53:383-390.

51. Gentry LE, Lioubin MN, Purchio AF, et al. Molecular events in the processing of recombinant type 1 pre-pro-transforming growth factor beta to the mature polypeptide. Mol Cell Biol 1988;8:4162-4168.

52. Isogai Z, Ono RN, Ushiro $\mathrm{S}$, et al. Latent transforming growth factor beta-binding protein 1 interacts with fibrillin and is a microfibril-associated protein. J Biol Chem 2003;278:2750-2757.

53. Boregowda R, Paul E, White J, et al. Bone and soft connective tissue alterations result from loss of fibrillin-2 expression. Matrix Biol 2008;27:661-666.

54. van der Slot AJ, van Dura EA, de Wit EC, et al. Elevated formation of pyridinoline cross-links by profibrotic cytokines is associated with enhanced lysyl hydroxylase $2 \mathrm{~b}$ levels. Biochim Biophys Acta 2005;1741:95-102. 